ARTICLE

\title{
Resensitizing carbapenem- and colistin-resistant bacteria to antibiotics using auranofin
}

\author{
Hongzhe Sun (1) 1,2,3,9凶 , Qi Zhang1,9, Runming Wang (1) 1,9凶, Haibo Wang ${ }^{1}$, Yuen-Ting Wong1,4, Minji Wang (1) 5 , \\ Quan Hao $\mathbb{D}^{6}$, Aixin Yan (1) ${ }^{5}$, Richard Yi-Tsun Kao ${ }^{4,7,8}$, Pak-Leung Ho (i) ${ }^{4,7,8}$ \& Hongyan $\mathrm{Li}^{1}$
}

Global emergence of Gram-negative bacteria carrying the plasmid-borne resistance genes, $b l a_{\mathrm{MBL}}$ and $m c r$, raises a significant challenge to the treatment of life-threatening infections by the antibiotics, carbapenem and colistin (COL). Here, we identify an antirheumatic drug, auranofin (AUR) as a dual inhibitor of metallo- $\beta$-lactamases (MBLs) and mobilized colistin resistance (MCRs), two resistance enzymes that have distinct structures and substrates. We demonstrate that AUR irreversibly abrogates both enzyme activity via the displacement of $\mathrm{Zn}$ (II) cofactors from their active sites. We further show that AUR synergizes with antibiotics on killing a broad spectrum of carbapenem and/or COL resistant bacterial strains, and slows down the development of $\beta$-lactam and $\mathrm{COL}$ resistance. Combination of AUR and $\mathrm{COL}$ rescues all mice infected by Escherichia coli co-expressing MCR-1 and New Delhi metallo- $\beta$ lactamase 5 (NDM-5). Our findings provide potential therapeutic strategy to combine AUR with antibiotics for combating superbugs co-producing MBLs and MCRs.

\footnotetext{
${ }^{1}$ Department of Chemistry, The University of Hong Kong, Pokfulam Road, Hong Kong, SAR, China. ${ }^{2}$ State Key Laboratory of Synthetic Chemistry, The University of Hong Kong, Pokfulam Road, Hong Kong, SAR, China. ${ }^{3}$ CAS-HKU Joint Laboratory of Metallomics on Health and Environment, The University of Hong Kong, The University of Hong Kong, Pokfulam Road, Hong Kong, SAR, China. ${ }^{4}$ Department of Microbiology, The University of Hong Kong, Sassoon Road, Hong Kong, SAR, China. ${ }^{5}$ School of Biological Sciences, The University of Hong Kong, Pokfulam Road, Hong Kong, SAR, China. ${ }^{6}$ School of Biomedical Sciences, The University of Hong Kong, Sassoon Road, Hong Kong, SAR, China. ${ }^{7}$ State Key Laboratory of Emerging Infectious Diseases, Carol Yu Centre for Infection, The University of Hong Kong, Hong Kong, SAR, China. ${ }^{8}$ The Research Centre of Infection and Immunology, Li Ka Shing Faculty of Medicine, The University of Hong Kong, Hong Kong, SAR, China. ${ }^{9}$ These authors contributed equally: Hongzhe Sun, Qi Zhang, Runming Wang. ${ }^{凶}$ email: hsun@hku.hk; u3002771@connect.hku.hk
} 
$\mathrm{T}$ he clinical efficacy of antibiotics has been severely challenged by plasmid-borne resistance determinants, in particular carbapenemase that renders Gram-negative bacteria resistant to carbapenem therapy, in either hospital or community settings, triggering the onset of the worldwide antimicrobial resistance crisis ${ }^{1}$. As one of the most clinically relevant carbapenemase, New Delhi metallo- $\beta$-lactamase 1 (NDM-1) has experienced the widest geographical spread since its discovery in $2008^{2}$.The resistance gene encoding NDM-1 $\left(b l a_{\mathrm{NDM}-1}\right)$ could be rapidly disseminated via plasmid as well as integrons cassette ${ }^{3}$ and expressed without apparent fitness cost among different bacteria $^{4}$. NDM-1 as well as other MBLs, confers bacterial resistance to nearly all available $\beta$-lactam antibiotics, leading to poor clinical outcomes of conventional antibiotic therapy ${ }^{5}$. Moreover, most $b l a_{\mathrm{MBL}}$-encoding plasmids co-harbored multiple resistance determinants, including serine- $\beta$-lactamase for monobactams, $16 \mathrm{~S}$ RNA methylases for aminoglycosides, rifampinmodifying enzymes for rifampin, chloramphenicol acetyltransferase for chloramphenicol, esterase for macrolides ${ }^{2,3,6}$, thus expanding to multidrug resistance and pandrug resistance.

As a consequence, the treatment of infections by NDM-1 producing clinical strains require the use of last-resort antibiotics e.g., $\mathrm{COL}^{7-9}$. COL acts by associating with the anionic lipopolysaccharide (LPS) component of Gram-negative outer membrane, leading to the disruption of the membrane, leakage of intracellular contents and ultimately lytic cell death ${ }^{10}$. Unfortunately, the efficacy of COL has been seriously compromised in the regular treatment of lethal bacterial infections owing to the emergence of MCR-1 enzyme since $2015^{11}$. Unlike chromosomally mediated polymyxin resistance, which is limited to clonal expansion ${ }^{12}$, the plasmid-borne $m c r-1$ (and its homologues, $m c r-2$ to -10$)^{13}$ is responsible for a transferable mechanism of polymyxin resistance and has been disseminated over 40 countries/regions covering five continents ${ }^{14}$. In addition to conferring resistance to polymyxin antibiotics, $m c r-1$ could also confer bacterial resistance toward lysozyme ${ }^{15}$. The situation gets exacerbated by the fact that $m c r-1$ could cotransfer with $m c r-3$ or $m c r-5^{16,17}$ and even coexist with $b l a_{\mathrm{MBL}}$ including $b l a_{\mathrm{NDM}-1}$ and its variants $b l a_{\mathrm{NDM}-5}$ and $b l a_{\mathrm{NDM}-9} 9^{18-21}$. Moreover, a clinical $E$. coli isolate has been found to co-carry $m c r-1, m c r-3$, and $b l a_{\mathrm{NDM}-5}$ genes $^{22}$. Thus, in clinic context, the co-existence of $\operatorname{MBL}(\mathrm{s})$ and $\mathrm{MCR}(\mathrm{s})$ in infectious pathogens has raised serious concerns that common infections with these "superbugs" may soon be untreatable, which will severely endanger public health system and leave clinicians with virtually no therapeutic options.

NDM-1, as a typical member of B1 class of MBLs, possesses two $\mathrm{Zn}(\mathrm{II})$ ions intercalated by a nucleophile hydroxide in its active site, which is delimited by flexible loop 3 and $10^{23}$. The two $\mathrm{Zn}$ (II) ions have been validated to be crucial for its hydrolytic activity to launch a nucleophilic attack on $\beta$-lactam rings in $\beta$ lactam antibiotics ${ }^{24}$. Additionally, the presence of $\mathrm{Zn}(\mathrm{II})$ ions is beneficial for the accumulation of MBLs in the bacterial periplasm owing to the rapid degradation of these enzymes in their non-metallated forms $\mathrm{s}^{25}$. MCR-1, a recent member of the phosphoethanolamine (PEA) transferase family, catalyzes the addition of the PEA moiety to the phosphoric group of lipid A moiety on LPS, rendering the bacterial membrane more electropositive and repelling cationic $\mathrm{COL}^{26}$. This enzyme contains a $\mathrm{Zn}$ (II) cofactor in its active site, coordinating to Glu246, Asp465, His466 and a conserved nucleophilic attack group, phosphorylated Thr285 $(\mathrm{TPO} 285)^{27,28}$. The $\mathrm{Zn}(\mathrm{II})$ ion in the active site of MCR-1 has been validated to be vital for the PEA transfer process; notwithstanding its biological roles in MCR proteins are still controversial ${ }^{29,30}$.

Our previous studies showed that an antipeptic ulcer bismuth drug, colloidal bismuth subcitrate, could resensitize MBL-positive bacteria to $\beta$-lactam antibiotics through kicking out the $\mathrm{Zn}$ (II) cofactors by $\mathrm{Bi}(\mathrm{III})$ from the active site of MBLs, thus disrupting their abilities to hydrolyze $\beta$-lactam ring in carbapenem ${ }^{31}$. We therefore hypothesize that a metallodrug-antibiotic combination serves as an effective strategy to combat "superbugs" that coproduce MBLs as well as other $\mathrm{Zn}$-dependent resistant determinants, e.g., MCRs. In the present study, we identified an antirheumatic drug, auranofin (AUR, its chemical structure is shown in Supplementary Fig. 1a) as an effective dual inhibitor of MBLs and MCRs. Our results showed that AUR irreversibly inhibit NDM-1 activity and disrupted the function of MCR-1 via displacing $\mathrm{Zn}(\mathrm{II})$ ions in the active sites and thus forming Au-NDM1 or Au-MCR-1. Importantly, AUR synergized with antibiotics on killing a spectrum of bacterial pathogens carrying $b a_{\mathrm{MBL}}$ and/ or $\mathrm{mcr}$ genes and significantly suppressed the resistance development of either MBL or MCR. Notably, AUR potently restored the susceptibility of MCR-1- and NDM-5-co-producing pathogens to COL in murine peritonitis models. This work clearly elucidates the antimicrobial action of a gold(I)-based drug and opens a horizon for the treatment of infections caused by superbugs carrying $b l a_{\mathrm{MBL}}$ and/or $m c r$ genes.

\section{Results}

Primary screening identifies auranofin as an antibiotic booster. A primary screening on a battery of metal compounds was performed to seek for COL and/or carbapenem (exemplified by meropenem, MER) synergism against E. coli CKE, a clinical isolate that co-produced NDM-5 and MCR-1 $\left(\mathrm{MIC}_{\mathrm{COL}}=\right.$ $\left.8 \mu \mathrm{g} \cdot \mathrm{mL}^{-1}, \mathrm{MIC}_{\mathrm{MER}}=32 \mu \mathrm{g} \cdot \mathrm{mL}^{-1}\right)$. The growth of $E$. coli CKE was examined in the presence of selected metal compounds at subinhibitory concentration $\left(50 \mu \mathrm{g} \cdot \mathrm{mL}^{-1}\right)$, and COL $\left(1 \mu \mathrm{g} \cdot \mathrm{mL}^{-1}\right)$ or MER $\left(2 \mu \mathrm{g} \cdot \mathrm{mL}^{-1}\right)$ for $18 \mathrm{~h}$. Our results showed that both cobalt(II) chloride and arsenic(III) trioxide could partially boost efficacies of both MER and COL with 50\% of microbial growth to be inhibited. However, Bi(III) (as bismuth nitrate) could only boost the activity of MER but not COL (Supplementary Fig. 1b, c). To our surprise, both $\mathrm{Au}(\mathrm{I})$ (as gold(I) chloride, $\mathrm{AuCl}$ ) and AUR were observed to markedly boost activities of either MER or COL to the extent that no bacterial growth was observed, suggesting its effectiveness on inhibiting both MBL and MCR-1 activity. In view of well-characterized toxicology and pharmacology of $\mathrm{AUR}^{32}$, we therefore selected AUR for further exploration of its potential as a dual inhibitor of MBLs and MCRs.

Auranofin inhibits NDM-1 hydrolytic activity. Native $\mathrm{Zn}_{2}$ NDM-1 protein was first overexpressed and purified according to previously described method ${ }^{31}$ to examine the inhibitory action of AUR towards MBLs. Since AUR is a prodrug and metabolizes to an active species $\left[\mathrm{Au}\left(\mathrm{PEt}_{3}\right)\right]^{+}$when transferred across cell membranes ${ }^{33}$, we therefore used an AUR analogue, chloro(triethylphosphine)gold(I) $\left[\mathrm{Au}\left(\mathrm{PEt}_{3}\right) \mathrm{Cl}\right]$, for all the enzyme-based biophysical studies to mimic its action in cellulo. The hydrolytic activity of NDM-1 against a chromogenic substrate, nitrocefin, was examined in the absence or presence of $\mathrm{Au}\left(\mathrm{PEt}_{3}\right) \mathrm{Cl}$ according to a previous report ${ }^{34}$. As shown in Fig. 1a, NDM-1 activity decreased as the $\mathrm{Au}\left(\mathrm{PEt}_{3}\right) \mathrm{Cl}$ concentration escalated $\left(\mathrm{IC}_{50}=\right.$ $437.9 \pm 29.1 \mathrm{nM}$ ), with $\sim 97 \%$ activity being inhibited, indicative of excellent inhibitory effect of AUR on NDM-1. From the enzyme kinetics assay, we found that $\mathrm{Au}\left(\mathrm{PEt}_{3}\right) \mathrm{Cl}$ leads to an evident decrease in the apparent $V_{\max }$ from $19.41 \mu \mathrm{M} \cdot \mathrm{min}^{-1}$ to $3.35 \mu \mathrm{M} \cdot \mathrm{min}^{-1}$ while the $K_{\mathrm{m}}$ value retained almost unchanged at around $\sim 67.3 \mu \mathrm{M}$, indicative of a typical noncompetitive inhibition (Fig. 1b). A plot of the inverse of the apparent maximal rates versus the concentration of the inhibitor allowed the inhibition 

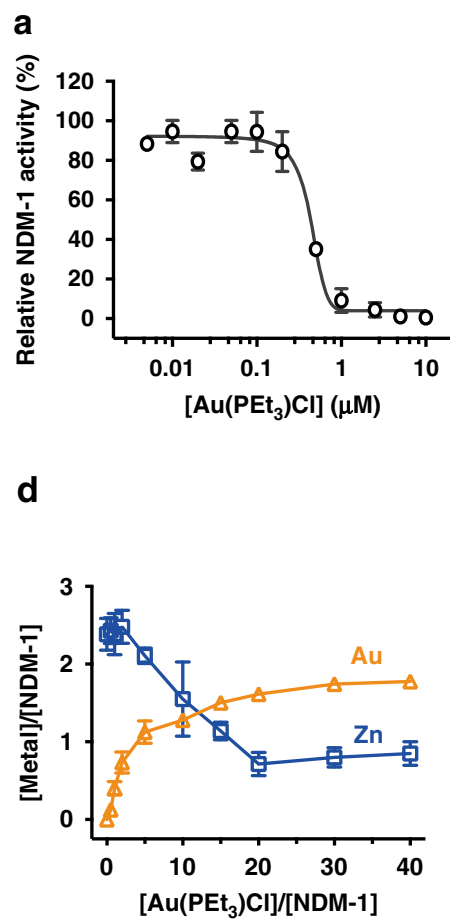

b

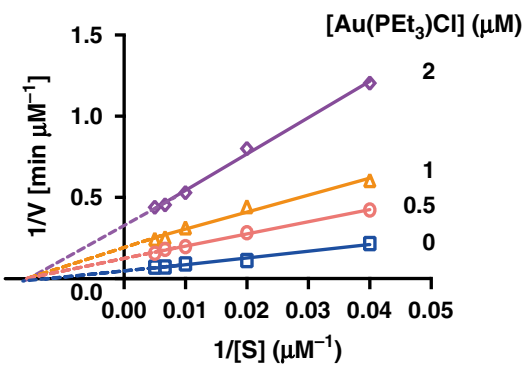

e

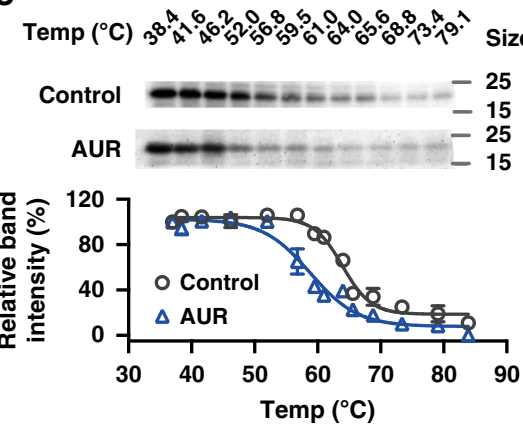

C

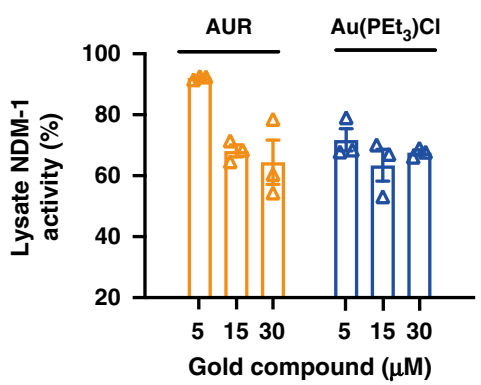

f

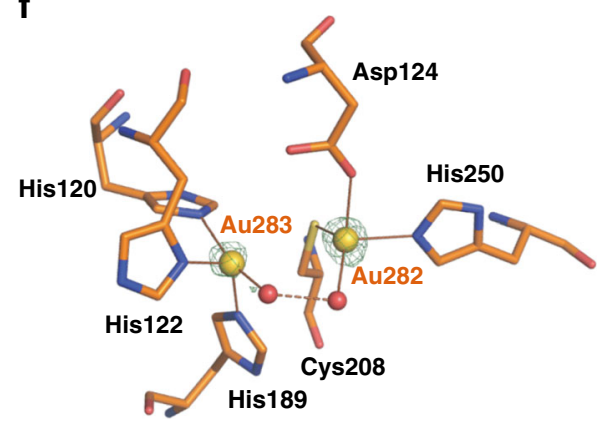

Fig. 1 Auranofin inhibits MBL activity via the displacement of $\mathbf{Z n}(\mathrm{II})$ cofactors. a Inhibition of NDM-1 activity by $\mathrm{Au}\left(\mathrm{PEt} \mathrm{t}_{3}\right) \mathrm{Cl}$ with $I \mathrm{C}_{50}$ of $437.9 \pm 29.1 \mathrm{nM}$. b Double reciprocal plot of substrate dependent enzyme kinetics on inhibition of NDM-1 activity by $\mathrm{Au}\left(\mathrm{PEt}_{3}\right) \mathrm{Cl}$. c Lysate NDM-1 activity from NDMRosetta treated with AUR or $\mathrm{Au}\left(\mathrm{PEt}_{3}\right) \mathrm{Cl}$. d The substitution of $\mathrm{Zn}(\mathrm{II})$ in $\mathrm{Zn}_{2}-\mathrm{NDM}-1$ by $\mathrm{Au}\left(\mathrm{PEt}_{3}\right) \mathrm{Cl}$ by equilibrium dialysis. The metal content was determined by ICP-MS. e Cellular thermal shift assays showing the binding of Au(I) to NDM-1 in intact NDM-Rosetta cells. NDM-1 melting temperature was shifted from 63.7 to $58.6^{\circ} \mathrm{C}$ for control and AUR-treated group, respectively. The images show the representative blottings of three independent experiments. $\mathbf{f}$ Structure of the active site of Au-NDM-1 (PDB ID: 6LHE) with the anomalous density peak of Au shown as yellow spheres and water molecules as red spheres, and anomalous density peak of $A u$ in green mesh contoured at $7.0 \sigma . \mathbf{a}, \mathbf{c}-\mathbf{e}$ Data are presented as mean values $\pm S E M, n=3$ biologically independent samples. Source data are provided as a Source Data file.

constant $\left(K_{\mathrm{i}}\right)$ to be calculated as $389.1 \mathrm{nM}$ for $\mathrm{Au}\left(\mathrm{PEt}_{3}\right) \mathrm{Cl}$. This suggests $\mathrm{Au}\left(\mathrm{PEt}_{3}\right) \mathrm{Cl}$ converted NDM-1 into an inactive state rather than competing for the active site with substrates.

It is commonly believed that AUR has a high affinity to thiolate sulfurs (cysteine residues) in proteins to form stable and irreversible adducts ${ }^{33}$. To examine the role of cysteine in NDM-1inhibition by AUR, we mutated Cys208 to Ala208, i.e., NDM-1-C208A. We found that the hydrolytic activity of the mutant was significantly reduced as demonstrated previously 31,35 . Its activity was inhibited by only $\sim 13.6 \%$ upon incubation with $\mathrm{Au}\left(\mathrm{PEt}_{3}\right) \mathrm{Cl}$ at $100 \mu \mathrm{M}$ (Supplementary Fig. 2), indicating that the interaction of AUR with Cys208 is important for its inhibition on NDM-1. Importantly, the lysates extracted from an engineered NDM-1 positive $E$. coli strain denoted as NDM-Rosetta, that exposed to overnight treatment of AUR (and $\mathrm{Au}\left(\mathrm{PEt}_{3}\right) \mathrm{Cl}$ ) at escalating concentrations, showed suppressed activity (up to $\sim 30 \%$ ) towards nitrocefin (Fig. 1c). These data demonstrated that AUR could effectively inhibit NDM-1 activity both in vitro and in cellulo.

Auranofin displaces $\mathrm{Zn}(\mathrm{II})$ cofactors with $\mathrm{Au}(\mathrm{I})$ in NDM-1. To explore the inhibitory role of AUR, we first examined its impact on the $\mathrm{Zn}$ (II) cofactors of NDM-1. By using 4-(2-pyridylazo) resorcinol (PAR) assay, we found that c.a. 1.09 molar equivalents of $\mathrm{Zn}$ (II) was gradually released from native $\mathrm{Zn}$-NDM-1 upon the addition of $\mathrm{Au}\left(\mathrm{PEt}_{3}\right) \mathrm{Cl}$ at $200 \mu \mathrm{M}$ (Supplementary Fig. 3a, b). In addition, the activity of Zn-NDM-1 was lost in a time-dependent manner when exposed to $\mathrm{Au}\left(\mathrm{PEt}_{3}\right) \mathrm{Cl}$ treatment (Supplementary Fig. 3c), indicating that the inhibition of NDM-1 by $\mathrm{Au}\left(\mathrm{PEt}_{3}\right) \mathrm{Cl}$ may be attributable to the deprivation of $\mathrm{Zn}$ (II). By using equilibrium dialysis, we showed that the addition of increasing amounts of $\mathrm{Au}\left(\mathrm{PEt}_{3}\right) \mathrm{Cl}$ to the native protein resulted in $\mathrm{ca}$. $1.77 \pm 0.08$ molar equivalents of $\mathrm{Au}(\mathrm{I})$ bound to NDM-1, accompanied by $c a$. $1.53 \pm 0.21$ molar equivalents of $\mathrm{Zn}(\mathrm{II})$ removal (Fig. 1d). The data were fitted by one-site binding Hill plot, which gave rise to the dissociation constant $\left(K_{\mathrm{d}}\right)$ of $4.03 \pm$ $0.65 \mu \mathrm{M}$ for $\mathrm{Au}\left(\mathrm{PEt}_{3}\right) \mathrm{Cl}$ and the maximal binding capacity $\left(B_{\text {max }}\right)$ of $1.95 \pm 0.10$, indicating that two $\mathrm{Au}(\mathrm{I})$ ions bound per monomer of NDM-1. Significantly, the inhibition of NDM-1 activity by $\mathrm{Au}$ $\left(\mathrm{PEt}_{3}\right) \mathrm{Cl}$ could not be reversed as the supplementation of 30 molar equivalents of $\mathrm{Zn}$ (II) led to less than $20 \%$ activity being restored for Au-NDM-1, owing to the limited ability of excess $\mathrm{Zn}$ (II) to replace $\mathrm{Au}(\mathrm{I})$ (Supplementary Fig. 4).

We next examined the binding of AUR to NDM-1 by matrix assisted laser desorption ionization time of flight mass spectrometry (MALDI-TOF MS) (Supplementary Fig. 5). A peak observed at $\mathrm{m} / z$ of 25925.4 could be assigned to NDM-1 monomer. After 18-h co-incubation with AUR at molar ratio of $1: 10$, new peaks at $m / z$ of $26124.3,26240.7,26323.1$, and 26442.9 appeared and could be assigned to [NDM-1 + Au], [NDM-1+ $\left.\left.\mathrm{Au}\left(\mathrm{PEt}_{3}\right)\right],[\mathrm{NDM}-1+2 \mathrm{Au})\right]$, and [NDM-1 $\left.\mathrm{Au}+\mathrm{Au}\left(\mathrm{PEt}_{3}\right)\right]$, respectively. These results suggested that $\left[\mathrm{Au}\left(\mathrm{PEt}_{3}\right)\right]^{+}$binds to NDM-1 via exchange triethlphosphine with the enzyme. The cellular engagement of NDM-1 by AUR was examined by cellular thermal shift assay (CETSA) ${ }^{36}$. The overnight exposure to AUR $\left(12 \mu \mathrm{g} \cdot \mathrm{mL}^{-1}\right)$ treatment decreased the cellular thermal stability of NDM- 1 by $\Delta \mathrm{T}_{\mathrm{m}}=5.2^{\circ} \mathrm{C}$ in NDM-Rosetta, indicative of the binding of AUR to NDM-1 in intact cells. (Fig. 1e).

We further explored the binding mode at atomic level by X-ray crystallography. Au-bound NDM-1 was first obtained by 
incubating apo-NDM-1 with 10 molar equivalents of AUR overnight at $25^{\circ} \mathrm{C}$ and then co-crystallized using a typical sittingdrop vapor diffusion method. The crystal structure of Au-NDM-1 was determined at $1.20 \AA$ resolution (PDB ID: 6LHE) and the binding of $\mathrm{Au}(\mathrm{I})$ to the protein was confirmed by X-ray excitation spectrum, which solely showed the excitation peak for gold ( $\mathrm{Au}$ L3) at the radiation energy around $9.8 \mathrm{keV}$, while no peak for zinc around $8.6 \mathrm{keV}$ was observed (Supplementary Fig. 6a). Superimposition of all its $\mathrm{Ca}$ atoms with Zn-NDM-1 (PDB ID: 5ZGE) showed no significant overall conformational changes $(\mathrm{RMSD}=$ $0.211 \AA$ ) (Supplementary Fig. 6b, c). As shown in Fig. 1f, two Au ions, viz, $\mathrm{Au}^{282}$ and $\mathrm{Au}^{283}$ were clearly observed in the active site, tetrahedrally coordinated to Cys208, His250, Asp124, a water molecule ( $\left.\mathrm{w}^{291}\right)$, and His122, His120, His189, and a water molecule $\left(\mathrm{w}^{410}\right)$, respectively. The distance between two Au ions $(\sim 3.8 \AA)$ is much shorter than that between two $\mathrm{Zn}$ ions $(\sim 4.6 \AA)$ in the intact NDM-1 crystal ${ }^{23}$. An additional $\mathrm{Au}$ ion $\left(\mathrm{Au}^{281}\right)$ resided in the interface of two protein monomers coordinating to Asp223, Glu152, a water molecule, and a Glu227 from an adjacent NDM-1 molecule in a distorted tetrahedral geometry (Supplementary Fig. 6d, e). The bond lengths of $\mathrm{Au}(\mathrm{I})$ with the side-chains of those amino acid residues were overall in the range of $1.9-2.5 \AA$ and generally comparable to those for $\mathrm{Zn}$ (II) (Supplementary Tables 1,2). The occupancies of the three Au ions were $c a .0 .5$ with the $\mathrm{Au}^{283}$ in the $\mathrm{Zn} 1$ site showing slightly lower occupancy (0.45). The active-site pocket of NDM-1 in the crystal structure was widely open and two Au ions resided in the bottom of the cavity, apparently being assessable to AUR. Overall, the data agreed well with our biophysical characterization that the Zn-dependent hydrolysis function of NDM-1 was inhibited by AUR through displacement of the $\mathrm{Zn}(\mathrm{II})$ in the active.

Auranofin resensitizes MBL-positive Enterobacteriaceae to carbapenem. We then examined whether AUR could enhance the antimicrobial activity of MER against an NDM-1 positive E. coli isolate, NDM-HK $\left(\mathrm{MIC}_{\mathrm{MER}}=16 \mu \mathrm{g} \cdot \mathrm{mL}^{-1}\right)^{37}$. The MIC value of MER was remarkably reduced by 64 folds in the presence of 16 $\mu \mathrm{g} \cdot \mathrm{mL}^{-1} \mathrm{AUR}$, for which the fractional inhibitory concentration index (FICI) was estimated to be 0.156 , i.e., indicative of synergy $($ FICI $\leq 0.5)$ (Fig. 2a). Importantly, the combination only led to additive killing of MBL negative strain with FICI of $0.625(0.5<$ FICI $<1$ indicates addition) during the same assay operations (Fig. 2b). The AUR-MER combination exhibited potent bactericidal effect as revealed by time-kill assay. Early-log phase culture of NDM-HK $\left(10^{6} \mathrm{CFU} \cdot \mathrm{mL}^{-1}\right)$ was subjected to the treatments of vehicle, MER, AUR or their combination; and the bacterial growth was measured at different intervals by agar plating. As expected, no evident CFU reduction of NDM-HK was observed among untreated, MER, and AUR group by $24 \mathrm{~h}$. In contrast, the bacterial loads in the combination group plummeted by more than five orders than any single component and their outgrowth were prevented throughout 24-h exposure (Fig. 2c). Furthermore, the antimicrobial potency of AUR-MER combination could be profiled against a panel of Enterobacteriaceae that produced either B1 MBL (VIM-2, IMP-4) or B2 MBL (CphA) (Fig. 2d), with FIC index ranged from 0.133 to 0.375 (Supplementary Table 3). This confirms that AUR serves as a broad-spectrum inhibitor of MBLs. Resistance levels to MER were greatly elevated upon exposure to MER at subinhibitory concentrations, as its MIC value increased by 8 -folds over a period of 16 serial passages (Fig. 2e). Importantly, the resistance level was slightly increased by 2 -folds upon the combined use of AUR and MER. In addition, in the presence of AUR $\left(30 \mu \mathrm{g} \cdot \mathrm{mL}^{-1}\right)$, the mutation prevention index (MPI) of MER significantly decreased from 32 to 1 (Fig. 2f). Our combined data clearly demonstrate that AUR restores the carbapenem activity against MBL-positive bacteria and restricts the enrichment of mutant subpopulation in them.

Auranofin disrupts action of MCR-1 catalysis. We next investigated the feasibility of AUR as a resistance breaker of MCR-1, which is devoid of cysteine residues in its active site. MCR-1 is organized into two domains including an $\mathrm{N}$-terminal inner membrane-bound domain and a soluble, periplasmic domain equipped with a $\mathrm{Zn}$-dependent catalytic core and two (putative) substrate-binding pockets ${ }^{38}$. This enzyme could bind PEA and lipid $A$ in respective pockets and launch the $\mathrm{Zn}$-dependent transfer of PEA to lipid A with the assistance of its transmembrane domain ${ }^{38}$. We asked whether AUR could functionally disrupt MCR-1 in vitro. To address this, the (semi-)activity of MCR-1 was measured by a thin layer chromatography (TLC)-based method using a fluorescently labeled natural mimetic substrate, nitrobenzodiazole-labeled glycerol-3phosphoethanolamine (NBD-glycerol-3-PEA) ${ }^{39}$. First, we purified the full-length membrane protein $\mathrm{Zn}-\mathrm{MCR}-1$ with a gradient concentration of the detergent $n$-dodecyl- $\beta$-D-maltoside (DDM) to preserve its catalytic activity. The protein was incubated with or without 10 molar equivalents of $\mathrm{Au}(\mathrm{I})$ compounds overnight and subsequently mixed with NBD-glycerol-3-PEA, followed by TLC detection. Zn-MCR-1 could cleave PEA group from NBDglycerol-3-PEA, and the loss of PEA group led to the faster migration of NBD-glycerol as revealed in Fig. 3a. In contrast, no observable migration relative to either the substrate only (as a control), $\mathrm{AuCl}$ or $\mathrm{Au}\left(\mathrm{PEt}_{3}\right) \mathrm{Cl}$ treatment group was found (Fig. 3a), indicative of the inhibition of cleavage activity of MCR1 by $\mathrm{Au}(\mathrm{I})$.

Given that membrane potential serves as a good indicator for the proper function of MCR-1 $1^{40}$, we further explored if AUR could disrupt the action of MCR-1 in intact cells. The membrane potentials of MCR-1 positive or negative Shigella flexneri (S. flexneri) was determined by using diethyloxacarbocyanine $\left[\mathrm{DiOC}_{2}(3)\right]$, a green fluorescent dye that formed red fluorescent aggregated with an increase in membrane potential, upon the treatment of $\mathrm{AUR}, \mathrm{Au}\left(\mathrm{PEt}_{3}\right) \mathrm{Cl}$, and carbonyl cyanide 3chlorophenylhydrazone (CCCP, as a positive control), respectively. As shown in Fig. 3b, green/red fluorescent ratios decreased from 6.14 to 4.08 , indicative of the significant reduction of the membrane negative charge in MCR-1 positive $S$. flexneri in comparison to the MCR-1 negative strain. Importantly, negligible reduction in negative charge was observed for MCR-1-positive S. flexneri that were treated either by AUR $(3 \mu \mathrm{M}), \mathrm{Au}\left(\mathrm{PEt}_{3}\right) \mathrm{Cl}$ $(3 \mu \mathrm{M})$, or CCCP $(5 \mu \mathrm{M})$ (Fig. $3 \mathrm{~b})$. This suggests that AUR effectively prevents the MCR-1-induced loss of negative charges in cellulo.

\section{Auranofin inhibits MCR-1 activity through displacement of Zn} (II) cofactor. To investigate the inhibitory effect of AUR, we first overexpressed and purified the soluble, periplasmic domain of truncated MCR-1 (residues 201-541, denoted as MCR-1-S), which was determined to bind three equivalents of $\mathrm{Zn}$ (II) ions by ICP-MS. We showed by PAR assay that titration of $\mathrm{Au}\left(\mathrm{PEt}_{3}\right) \mathrm{Cl}$ (10 molar equivalents) to the Zn-MCR-1-S led to $c a .1 .98$ molar equivalents of $\mathrm{Zn}$ (II) to be released from the protein rapidly within 30 min (Supplementary Fig. 7). By equilibrium dialysis, we found unexpectedly that $\mathrm{Au}(\mathrm{I})$ ions bind intact MCR-1-S (ZnMCR-1-S) with the binding affinities $\left(K_{\mathrm{d}}\right)$ of $3.36 \pm 0.38 \mu \mathrm{M}$ for $\mathrm{Au}\left(\mathrm{PEt}_{3}\right) \mathrm{Cl}$ and binding stoichiometry $\left(B_{\text {max }}\right)$ of $3.00 \pm 0.60 . \mathrm{Zn}$ (II) content in Zn-MCR-1-S was decreased gradually and ca. 2.21 molar equivalents of $\mathrm{Zn}$ (II) was removed ultimately during the exposure to $\mathrm{Au}\left(\mathrm{PEt}_{3}\right) \mathrm{Cl}$ (Fig. 3c). Notably, the supplementation of up to 5 molar equivalents of $\mathrm{Zn}$ (II) could not displace $\mathrm{Au}$ (I) 
a
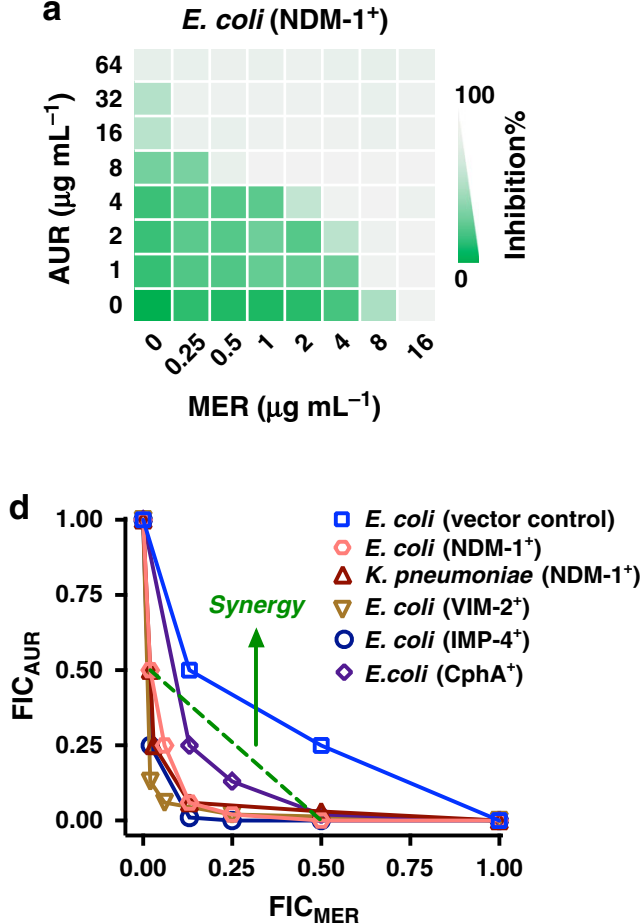

b

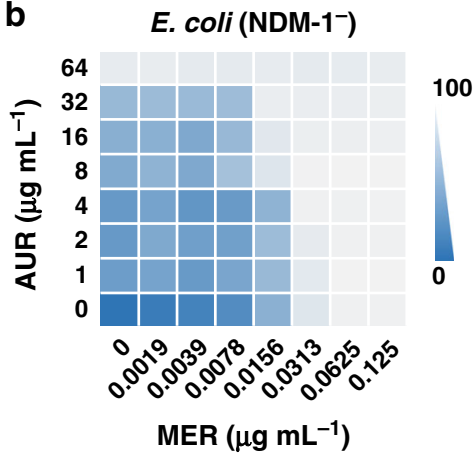

e

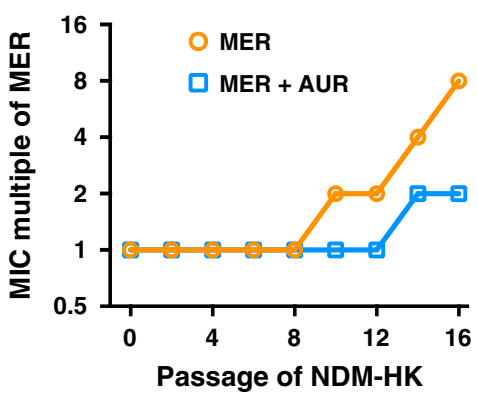

C

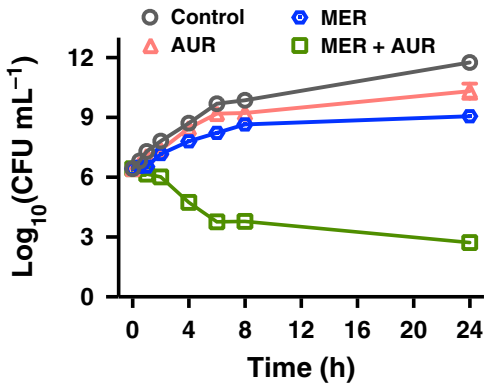

f

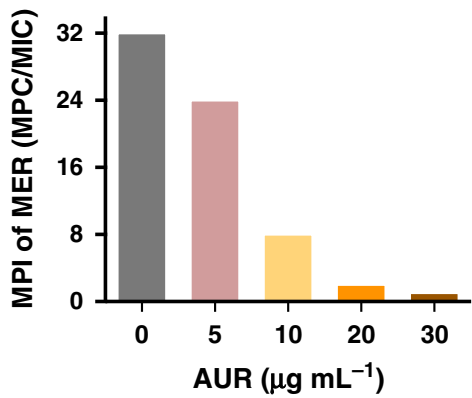

Fig. 2 Auranofin restores the susceptibility of $\mathbf{M B L}$-positive bacteria to carbapenem. $\mathbf{a}$, $\mathbf{b}$ Representative heat plots of microdilution checkerboard assays for the combination of MER and AUR against (a) NDM-1-positive E. coli and (b) NDM-1-negative E. coli. c Time-kill curves for MER or AUR monotherapy or

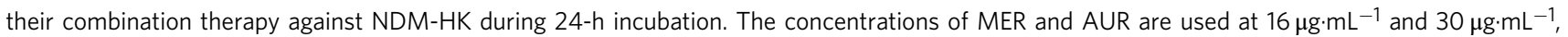
respectively. Data are presented as mean values $\pm \mathrm{SEM}, n=3$ biologically independent samples. $\mathbf{d}$ Isobolograms of the combination of MER and AUR against different MBL-positive bacterial strains. The green dash line indicates ideal isobole, where drugs act additively and independently. Data points

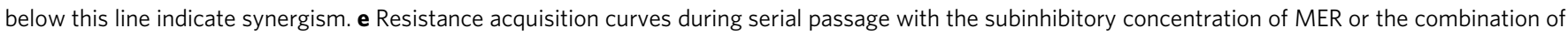
MER and AUR against NDM-HK. MIC test was performed every two passages. $\mathbf{f}$ Bar chart showing MPI indices of MER in the presence of increasing concentration of AUR against NDM-HK. $\mathbf{a}, \mathbf{b}$ Data in $\mathbf{a}$ and $\mathbf{b}$ represent the mean $\mathrm{OD}_{600}$ of two biological replicates. Source data are provided as a Source Data file.

from Au-MCR-1-S (Fig. 3d). These data suggest that AUR disrupts the function of MCR-1 via displacement of $\mathrm{Zn}$ (II) by $\mathrm{Au}(\mathrm{I})$. We next investigated cellular engagement of MCR-1-S by AUR using CETSA, the thermal stability of MCR-1-S was decreased by ca. $3.6^{\circ} \mathrm{C}\left(\Delta \mathrm{T}_{\mathrm{m}}\right)$ upon treatment of AUR $\left(15 \mu \mathrm{g} \cdot \mathrm{mL}^{-1}\right)$ in MCR1-S-producing E. coli (denoted as MCR-1-S-BL21) (Fig. 3e), confirming the binding of AUR to MCR-1 in cellulo.

To further unveil the detailed inhibition mode, we first prepared a Zn-bound crystal of MCR-1-S (PDB ID: 6LI4) and then transformed to Au-bound MCR-1-S crystal (PDB ID: 6LI6) by a soaking method ${ }^{31}$. The crystal structure of Au-MCR-1-S was resolved at $1.68 \AA$ resolution and the binding of $\mathrm{Au}(\mathrm{I})$ to the MCR-1-S was also confirmed by X-ray excitation spectrum (Supplementary Fig. 8). Superimposition of this crystal structure with the Zn-bound or apo-bound MCR-1-S (PDB ID: 6LI5) overall $\mathrm{C}_{a}$ atoms showed negligible overall conformational change with RMSD values of 0.476 and $0.573 \AA$, respectively (Supplementary Fig. 9). From the density map, three Au ions were clearly visible in one chain in an asymmetric unit, and a single $\mathrm{Au}$ ion $\left(\mathrm{Au}^{542}\right.$ with occupancy of 0.5$)$ was found in the $\mathrm{Zn}$-dependent catalytic core, coordinating with four residues, i.e., Glu246, Asp465, His466, and TPO285 to form a distorted tetrahedral geometry (Fig. 3f). The bond lengths of $\mathrm{Au}(\mathrm{I})$ with the side-chains of amino acid residues are overall slightly longer than those for $\mathrm{Zn}$ (II) (Supplementary Tables 4, 5), probably owing to the larger ionic radius of $\mathrm{Au}(\mathrm{I})(1.37 \AA)$ than $\mathrm{Zn}(\mathrm{II})(0.74 \AA)$. The second $\mathrm{Au}$ ion $\left(\mathrm{Au}^{543}\right)$ linearly coordinated to $\mathrm{N \varepsilon} 2$-His252 and $\mathrm{PEt}_{3}$ group (N-Au-P angle $171.5^{\circ}$ ) (Supplementary Fig. 10). The third $\mathrm{Au}$ ion $\left(\mathrm{Au}^{544}\right)$ coordinated to $\mathrm{N \varepsilon 2}$-His424 and a water molecule in a quasi-linear geometry $\left(\mathrm{N}-\mathrm{Au}-\mathrm{O}\right.$ angle of $159.0^{\circ}$ ) (Supplementary Fig. 10). The $\mathrm{Au}$ ion $\left(\mathrm{Au}^{543}\right)$ was only observed in one chain in the asymmetric unit with occupancy of $\sim 0.3$, but not in the other one (Supplementary Fig. 10a), inferring the less accessibility of $\mathrm{Au}\left(\mathrm{PEt}_{3}\right) \mathrm{Cl}$ to this site. The crystallographic analysis demonstrates that AUR binds to MCR-1 and displaces $\mathrm{Zn}(\mathrm{II})$ in the active site through $\mathrm{Au}(\mathrm{I})$.

Auranofin resensitizes MCR-positive Enterobacteriaceae to colistin. By using checkerboard microdilution assay, we observed a synergistic pattern that AUR $\left(5 \mu \mathrm{g} \cdot \mathrm{mL}^{-1}\right)$ resensitized MCR-1J53 to COL by 64 folds, with its MIC dropped from $8 \mu \mathrm{g} \cdot \mathrm{mL}^{-1}$ to $0.125 \mu \mathrm{g} \cdot \mathrm{mL}^{-1}$ (Fig. 4a). This combination showed typical synergism with FIC index of 0.125 for MCR-1-J53 but not for MCR-1-negative strain (FIC $=0.531$, Fig. 4b). Time-kill assay revealed that AUR $\left(6 \mu \mathrm{g} \cdot \mathrm{mL}^{-1}\right)$ and COL $\left(2 \mu \mathrm{g} \cdot \mathrm{mL}^{-1}\right)$ combinedly presented a potent bactericidal activity as reflected by over $10^{7}$ decreases in viable MCR-1-J53 compared with the control or any single components after 24-h exposure (Fig. 4c). Furthermore, the two drugs synergized to kill a spectrum of MCR-positive bacterial pathogens with the MIC of COL above susceptible breakpoint $\left(2 \mu \mathrm{g} \cdot \mathrm{mL}^{-1}\right)$ and FIC index ranging from 0.125-0.281 (Fig. 4d and Supplementary Table 6). Under identical conditions, AUR $\left(0.625 \mu \mathrm{g} \cdot \mathrm{mL}^{-1}\right)$ significantly decreased the MIC of COL against an E. coli strain produced different MCR variants including $5 \mathrm{MCR}-1$ variants and $6 \mathrm{MCR}$ homologs, by 8-16-folds (Fig. 4e), implying the broad-spectrum antimicrobial potency of this combination against $\operatorname{MCR}(\mathrm{s})$-positive bacteria. 
a

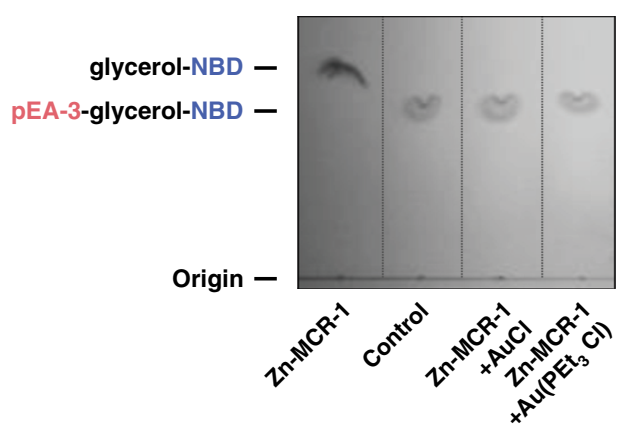

d

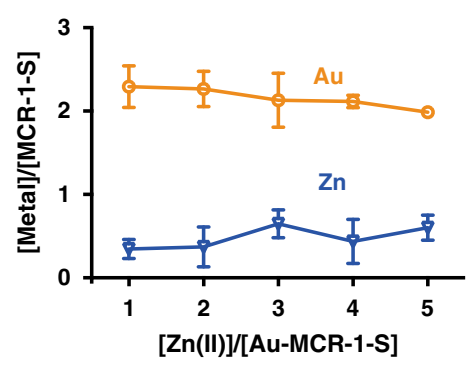

b

\section{S. flexneri (MCR-1-) S. flexneri (MCR-1 ${ }^{+}$)}

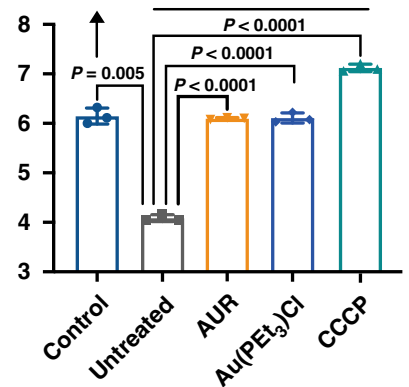

e

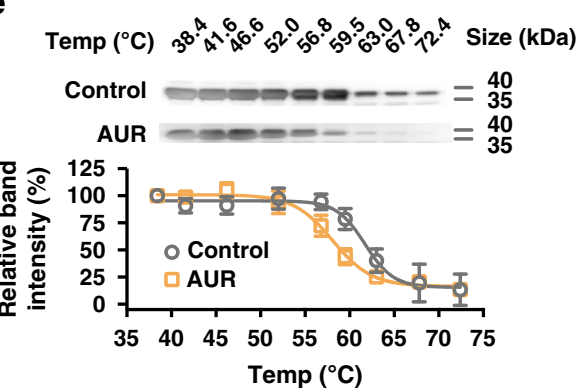

C

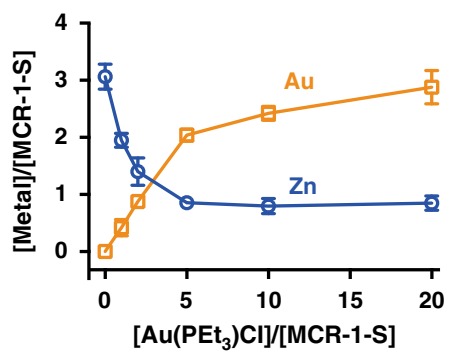

f

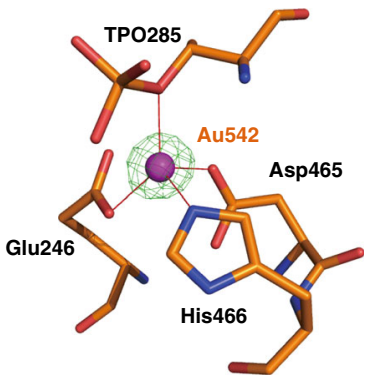

Fig. 3 Auranofin disrupts the Zn(II)-dependent function of MCR-1. a Inhibition of MCR-1 cleavage activity on NBD-glycerol-3-PEA by AuCl and Au(PEt 3 ) $\mathrm{Cl}$. A representative image of TCL plate is shown here. $\mathbf{b}$ Membrane potential changes upon AUR treatment in MCR-1 positive and negative S. flexneri as determined by the ratios of green to red fluorescent signals. c Substitution of $\mathrm{Zn}(\mathrm{II})$ in $\mathrm{Zn}_{3}-\mathrm{MCR}-1-\mathrm{S}$ by $\mathrm{Au}\left(\mathrm{PEt}{ }_{3}\right) \mathrm{Cl}$ over equilibrium dialysis. The metal content was determined by ICP-MS. d The metal contents upon supplementation of various amounts of $\mathrm{Zn}$ (II) into Au-MCR-1-S over equilibrium dialysis. The metal content was determined by ICP-MS. e Cellular thermal shift assays showing the binding of Au(I) to catalytic domain of MCR-1 in intact MCR-1-SBL21 cells. MCR-1-S melting temperature was shifted from 61.7 to $58.1^{\circ} \mathrm{C}$ for control and AUR-treated group, respectively. The images show the representative blottings of three independent experiments. $\mathbf{f}$ Structure of the active site of Au-MCR-1-S (PDB ID: 6LI6) with the anomalous density peak of Au ion shown as a purple sphere and anomalous density peak of $A u$ in magenta mesh contoured at $5 \sigma . \mathbf{b}-\mathbf{e}$ Data are presented as mean values \pm SEM, $n=$ 3 biologically independent samples. $\mathbf{b} P$ values were determined by an unpaired two-tailed student $t$-test with Welch's correction. Source data are provided as a Source Data file.

The in vitro serial passage was also used to examine whether AUR could suppress the resistance development in MCR-1 positive bacteria. We showed that the MIC values of COL increased by 100 folds after a period of 16 serial passages when used alone (Fig. 4f). In contrast, the MIC values of COL was increased only by 4 folds at the end of experiment upon the combined use of AUR. Similar to the result of MPC assay for NDM-1, AUR decreased the mutation prevention indices (MPI) of COL by 32 folds, i.e., from 16 to 0.5 in a dosedependent manner (Fig. 4g), suggesting that AUR serves to diminish the occurrence of higher level of resistance in Enterobacteriaceae.

Auranofin restores in vivo efficacy of colistin. To further evaluate the potential utility of combination regimens, we assessed AUR in combination with COL in vivo using two murine models of MCR-1- and -NDM-5-positive E. coli and MCR-1-positive K. pneumoniae infections. AUR was dosed at subinhibitory concentrations, which exhibited synergistic potentiation based on in vitro assessing (Figs. 2, 4, Supplementary Tables 3, 6), and were below the toxicity dosage according to a pilot study. COL was administrated at approximately human equivalent dose (daily dosage: $2.5-5.0 \mathrm{mg} \cdot \mathrm{kg}^{-141,}$ ). Balb/c mice were first systemically infected intraperitoneally (i.p.) with a sublethal dose of K. pneumoniae $\left(\mathrm{MCR}-1^{+}\right)\left(\sim 2 \times 10^{6} \mathrm{CFU}\right.$ per mouse), and then administrated with single dose of vehicle, AUR $\left(0.5 \mathrm{mg} \cdot \mathrm{kg}^{-1}\right)$, COL $\left(2 \mathrm{mg} \cdot \mathrm{kg}^{-1}\right)$ or their combination 1 -h post-infection, respectively. The bacterial loads in the liver and spleen were barely affected by
AUR alone and the isolate showed certain extent of resistance to COL monotherapy after $48 \mathrm{~h}$. In contrast, the bacterial loads of COL-AUR combination group plummeted by over 10 folds in the spleen and liver than that of COL alone (Fig. $5 \mathrm{a}, \mathrm{b}$ ). In a separated model, groups of Balb/c mice were i.p. injected with lethal dose of E. coli $\mathrm{CKE}$, and received single dose of AUR, COL or their combination 0.5 -h post-infection, respectively. We found that both vehicle control and AUR alone led to the death of all mice in respective group within 3 days, and COL monotherapy failed to rescue four out of six infected mice till the endpoint of experimental period. Remarkably, all mice were survived upon the combination therapy at 5 days following infection (Fig. 5c), highlighting the in vivo effectiveness of AUR-COL combination against MCR-1- and -NDM-5-positive bacterial infections.

\section{Discussion}

The dissemination of MBL-producing Enterobacteriaceae, as well as the acquisition of polymyxin resistance gene $m c r-1$ in those bacteria, may lead to the emergence of untreatable bacterial infections, thus posting significant threat to healthcare systems globally. With little remission from the therapeutic reliance on the current pipeline of $\beta$-lactam antibiotics and COL, the combination therapy consisting of an antibiotic resistance and an antibiotic breaker offers promising options to narrow the gap between pan-resistant bacteria and the development of new antibiotics. In this connection, recent studies have reported a number of mechanism-based or structure-based inhibitors of NDM-1 and other MBLs, primarily including covalent inhibitor 
a
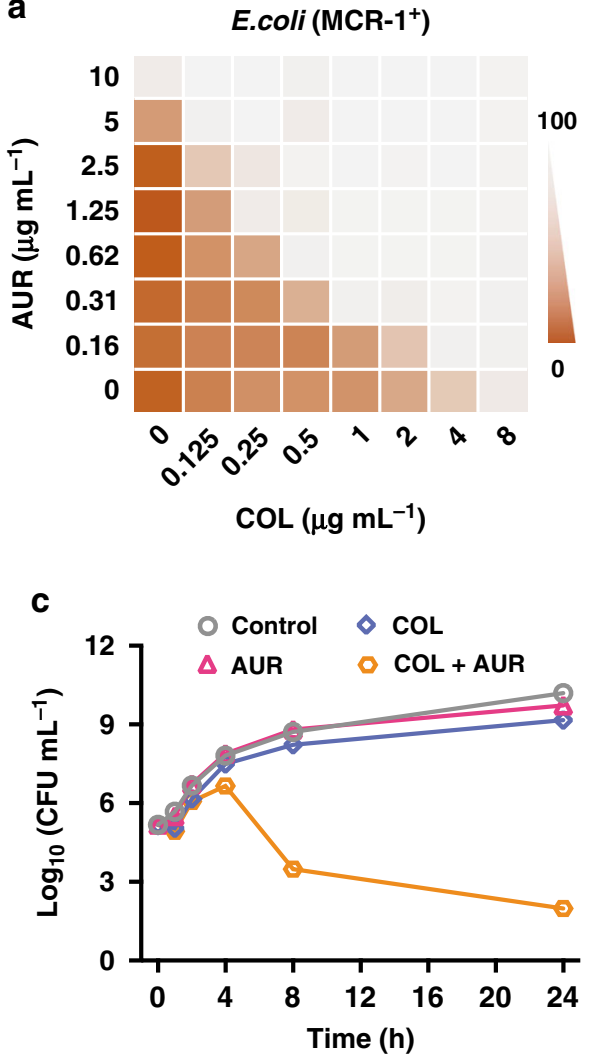

b

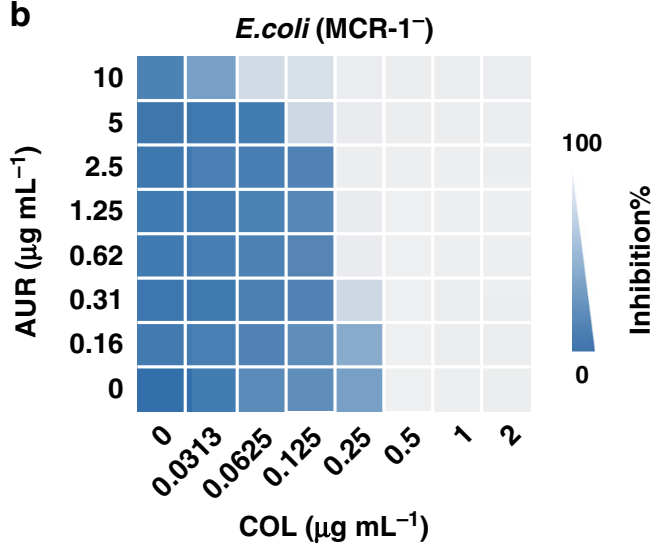

e

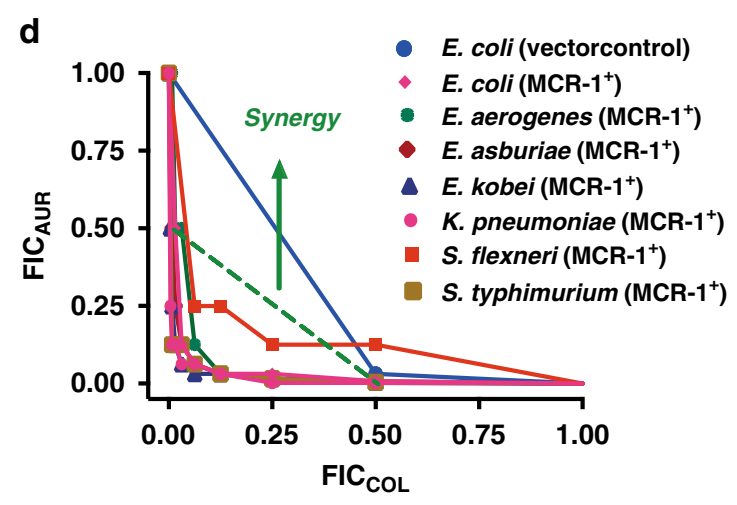

E. coli producing MCR variants

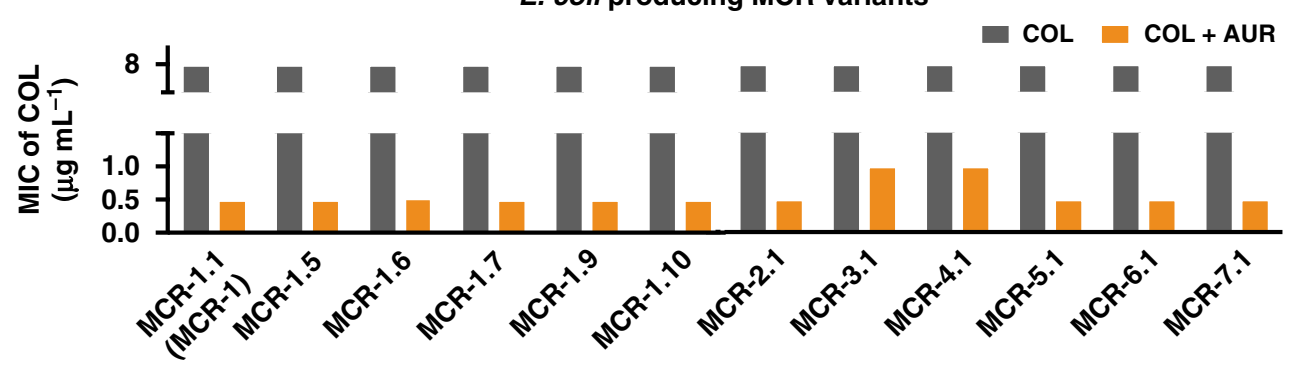

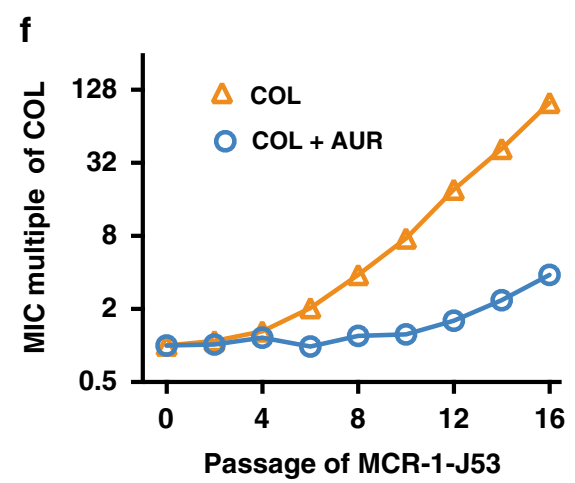

( $\beta$-lactam and non- $\beta$-lactam inhibitor), and non-covalent inhibitors (e.g., zinc chelate and coordinating agent) ${ }^{42}$. In parallel, other strategies have also been developed to restore COL sensitivity to MCR-1-postivie bacteria, by combined use with other antimicrobial agents (e.g., clarithromycin ${ }^{43}$ ), or substrate mimickers (e.g., ethanolamine ${ }^{44}, \mathrm{D}$-glucose ${ }^{44}$ ). However, owing to the vast differences in the active sites and modes of action between MBLs and MCRs, no inhibitors are available clinically to

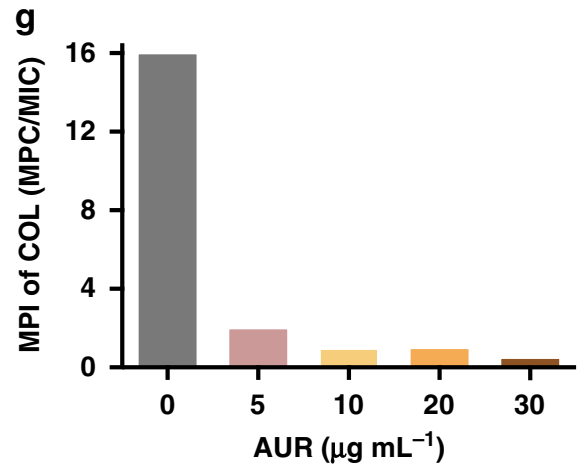

inhibit both enzymes simultaneously. Here, we propose AUR as a promising dual inhibitor of MBL and MCR enzymes. AUR serves as an antibiotic adjuvant to resensitize MBL- and/or MCRpositive bacteria to carbapenem and COL, and slows down the development of higher level of resistance. Importantly, the combination of AUR and COL showed therapeutic potency for the treatment of infections caused by carbapenem-and polymyxin-resistant bacteria at subclinical doses in vivo. 
Fig. 4 Auranofin synergizes with colistin to kill MCR-positive bacterial strains. a, b Representative heat plots of microdilution checkerboard assay for the combination of COL and AUR against a MCR-1-positive E. coli and $\mathbf{b}$ MCR-1-negative E. coli. c Time-kill curves for COL and AUR monotherapy or combination therapy against MCR-1-J53 during 24-hr incubation. The concentrations of COL and AUR are $2 \mu \mathrm{g} \cdot \mathrm{mL}^{-1} \mathrm{and} 6 \mu \mathrm{g} \cdot \mathrm{mL}^{-1}$, respectively. Data are presented as mean values \pm SEM,$n=3$ biologically independent samples. $\mathbf{d}$ Isobolograms of the combination of COL and AUR against different MCR-1positive bacterial strains. The green dash line indicates ideal isobole, where drugs act additively and independently. Data points below this line indicate synergism. e Bar charts showing the reduction of COL MIC for E. coli J53 that produced MCR-1 variants and MCR homologs in the combined use with AUR at fixed concentration of $0.625 \mu \mathrm{g} \cdot \mathrm{mL}^{-1}$. $\mathbf{f}$ Resistance acquisition curves during serial passage with the subinhibitory concentration of $\mathrm{COL}$ or the combination of COL and AUR against MCR-1-J53. MIC test was performed every two passages. $\mathbf{g}$ Bar charts showing MPI indices of MER in the presence of increasing concentration of AUR against MCR-1-J53. $\mathbf{a}, \mathbf{b}$ Data in $\mathbf{a}$ and $\mathbf{b}$ represent the mean $\mathrm{OD}_{600}$ of two biological replicates. Source data are provided as a Source Data file.

a

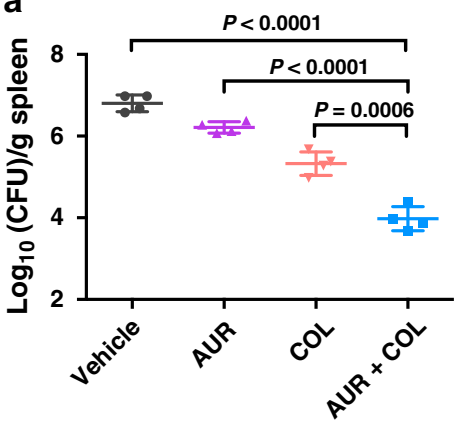

b

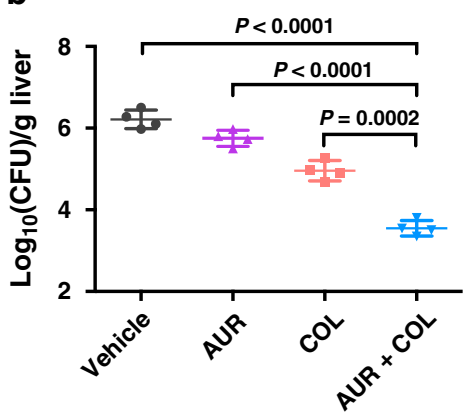

c

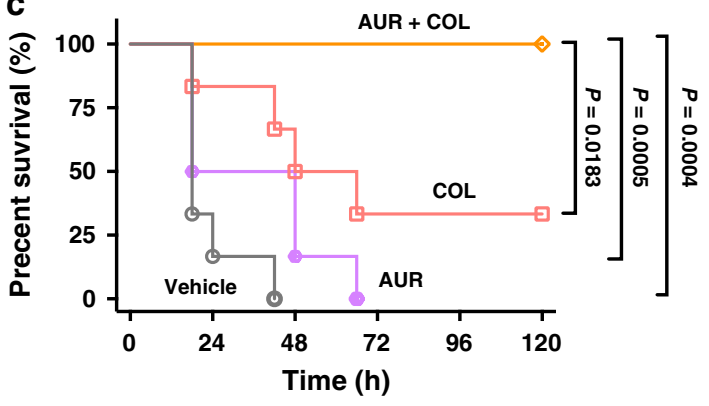

Fig. 5 The combination of AUR and COL shows potency in vivo. a, b Balb/c mice were given a sublethal dose of $K$. pneumoniae 9607 (MCR- $1^{+}$) and received single dose of i.p. administration of vehicle, AUR, COL or their combination ( $n=4$ per group). Bacterial loads in the spleen (a) and liver (b) are shown. c Survival curves showing combination efficacies in the peritonitis infection model. Balb/c mice were infected by a lethal dose of $E$. coli CKE (MCR-1+, $\mathrm{NDM}-5^{+}$) and received single dose of i.p. administration of vehicle, AUR, COL or their combination ( $n=6$ per group). $\mathbf{a}, \mathbf{b}$ Error bars represent mean \pm SEM for biological replicates. a, b $P$ values were determined by an unpaired two-tailed student $t$-test with Welch's correction. For a $P<0.0001$, significance difference between AUR $+\mathrm{COL}$ and Vehicle or AUR group, $P=0.0006$, significance difference between $\mathrm{AUR}+\mathrm{COL}$ and $\mathrm{COL}$. For $\mathbf{b}$, a $P<0.0001$, significance difference between AUR $+\mathrm{COL}$ and Vehicle or AUR group, ${ }^{\star \star \star} P=0.0002$, significance difference between AUR $+\mathrm{COL}$ and COL. $\mathbf{c} P$ values were determined by two-tailed Log-rank (Mantel-Cox) test. $P=0.0004$, significance difference between $A U R+C O L$ and vehicle group, $P=0.0005$, significance difference between AUR + COL and AUR group, $P=0.0183$, significance difference between $A U R+C O L$ and COL group. Source data are provided as a Source Data file.

Although the exact molecular mode of action of AUR has not been fully understood, it is believed to be associated with its strong thiophilic nature. In general, AUR metabolizes into a $[\mathrm{Au}$ $\left.\left(\mathrm{PEt}_{3}\right)\right]^{+}$species via an exchange of its tetraacetylated thioglucose ligand with cellular or blood thiols, and then targets cysteine residues (and/or histidine residues), or redox-active selenocysteine through thiolate exchange ${ }^{45}$. In spite of occupying similar positions with $\mathrm{Zn}(\mathrm{II})$ in both enzymes, $\mathrm{Au}(\mathrm{I})$ normally prefers linear coordination (two-coordination) with four-coordination being less frequent and hardly has five-coordination. Ligand exchange in $\mathrm{Au}(\mathrm{I})$ complex is much slower than that of $\mathrm{Zn}(\mathrm{II})$, particularly for tetrahedral $\mathrm{Au}(\mathrm{I})$ complexes $^{46}$. Moreover, the differences and affinities towards water between $\mathrm{Zn}(\mathrm{II})$ and $\mathrm{Au}(\mathrm{I})$ may largely alter the activated energy of transition state and thus makes the catalytic process no longer work under the same condition, leading to inhibition of the enzymes upon $\mathrm{Zn}$ (II) displacement by $\mathrm{Au}(\mathrm{I})$.

Our combined data have demonstrated that AUR could break the resistance mediated by $\mathrm{B} 1$ and $\mathrm{B} 2$ class MBLs via targeting the cysteine residue in the active site of those enzymes. The emanation of $\left[\mathrm{Au}\left(\mathrm{PEt}_{3}\right)\right]^{+}$from AUR and its binding to NDM-1 could be well characterized by the MALDI-TOF MS data (Supplementary Fig. 4). Our crystallographic analysis confirmed the binding of $\mathrm{Au}(\mathrm{I})$ species to the cysteine residue at the active site of NDM-1 (Fig. 1f). Unlike bismuth ${ }^{31}$, each AUR displaces one Zn (II) and tetrahedrally coordinated to respective three residues in either Zn1 or Zn2 site of NDM-1. The loss of inhibitory activity of AUR for C208A NDM-1 mutant confirmed the importance of cysteine during the engagement of AUR to NDM-1
(Supplementary Fig. 3b). This feature suggests that AUR could be used as a broad-spectrum inhibitor of B1 and B2 class of MBL to efficiently resensitize carbapenem-resistant bacteria to conventional antibiotics, as revealed by our susceptibility testing data (Fig. 2 and Supplementary Table 3).

Previous studies have shown that all the members of the MCR family proteins possess an identical secondary structure, with a high degree of conservation for the amino acid residues in the active site and PEA-interacting cavities. In particular, residues Glu246, Thr285, His390, Asp465, and His466 in the zinc-binding core and residues Asn108, Thr112, Glu116, Ser330, Lys333, His395, and His478 in the PEA binding cavity in MCR-1 are also located in similar positions in other MCR members ${ }^{47}$. Although there is no cysteine residues in the active site of MCR enzyme, to our surprise, unlike $\mathrm{Bi}(\mathrm{III})$ drugs, AUR also targets MCR-1 protein at its zinc-catalytic core through the side-chains $(\varepsilon N)$ of histidine residues, suggesting that the "softness" of histidine (e.g., $\varepsilon N$ ) is tunable by a protein. Indeed, the unique chemistry of metal ions has recently aroused great interests in using metalloagents for combating antimicrobial resistance ${ }^{48}$. We show that the $\mathrm{Zn}$ (II) ions in MCR-1 could be irreversibly kicked out by AUR (Fig. 3c, d) and form an Au-bound MCR-1 with Au(I) coordinating to Glu246, Asp465, His466, and TPO285 (Fig. 3f). As a consequence, AUR functionally disrupts MCR-1 in its cleavage action of PEA from the substrate, resulting in prevention of MCR-1 from perturbing the negative charges on bacterial membrane (Fig. 3b, c). Importantly, AUR was found to restore the susceptibility of bacteria carrying $m c r-1$ gene or its variants/ homologs to COL at concentrations below clinical breakpoint 
(resistant breakpoint $>2 \mu \mathrm{g} \cdot \mathrm{mL}^{-1}$ for Enterobacteriaceae), indicative of its broad-spectrum inhibitory activity against MCR family proteins (Fig. 4a-e). We hypothesize that, upon the inhibition of MCR-1 by AUR on cell membrane, COL may act as a membrane-disrupting agent ${ }^{49}$ to in turn facilitate the uptake of hydrophobic AUR in Gram-negative bacteria. Given that the MCR members are functional, unified, and equivalent, these findings would constitute a structural and mechanistic paradigm for further development of MCR-1 inhibitors to circumvent COL resistance.

Despite the rapid evolution of either NDM-1 or MCR-1 into their variants with higher resistant level ${ }^{50,51}$, we demonstrate that AUR could suppress the resistance development (Figs. 2e and 4f). The inability to generate a resistant mutant is likely due to the fact that AUR has multiple targets or possesses a nonspecific mode of action in E. coli ${ }^{52}$. As shown in Figs. $2 \mathrm{f}$ and $4 \mathrm{~g}$, in the presence of AUR $\left(30 \mu \mathrm{g} \cdot \mathrm{mL}^{-1}\right)$, the mutation prevention indices (MPI) of MER and COL were decreased by 32 folds, suggesting that the combined use of AUR restricted the enrichment of mutant subpopulation. The area under the curve $\left(\mathrm{AUC}_{24}\right) / \mathrm{MPC}$ and peak plasma concentration $\left(\mathrm{C}_{\max }\right) / \mathrm{MPC}$ values were considered to be two more accurate predictive indices of activity against resistant mutant than $\mathrm{AUC}_{24} / \mathrm{MIC}$ and $\mathrm{C}_{\max } / \mathrm{MIC}$, with optimal values of $>25$ and $>2.2$, respectively. Based on our data, $\mathrm{AUC}_{24} / \mathrm{MPC}$ and $\mathrm{C}_{\max } / \mathrm{MPC}$ could be preliminarily estimated to be 29.2 and 2.9 for MER (MERREM ${ }^{\circledR}$ IV, meropenem for injection, for intravenous use, FDA, 1996) and 15 and 0.63 for COL (calculated with steady-state COL $\mathrm{AUC}_{\mathrm{ss}, 0-24}$ of $60 \mu \mathrm{g} \cdot \mathrm{h} \cdot \mathrm{mL}^{-1}$ and $\mathrm{C}_{\mathrm{ss}}$, average of $\left.2.5 \mu \mathrm{g} \cdot \mathrm{mL}^{-1}\right)^{53}$, respectively, demonstrating that the combined use of AUR may serve to lower the emergence of higher-level resistant mutants in clinic.

Notably, the therapeutic potential has been demonstrated by our in vivo data that AUR-COL combination is highly effective in eradicating MCR-1-positive bacteria in peritonitis infection model. Co-administration with AUR (0.25-0.5 mg.kg $\left.{ }^{-1}\right)$ restores the in vivo efficacy of COL, with over 10 -fold reduction in K. pneumoniae loads in mouse liver and spleen (Fig. 5a, b), as well as completely prevents the death of the group of mice infected by MCR-1- and NDM-5-positive E. coli (Fig. 5c). AUR was approved by the FDA as an oral anti-inflammatory aid in the treatment of rheumatoid arthritis ${ }^{32}$ with well documented with no carcinogenicity, no side-effects, or no other long-term safety concerns ${ }^{32}$, and is now undergoing a phase II clinical trial for the treatment of amebiasis or giardiasis ${ }^{54}$. At the currently FDA-approved longterm dose ( $6 \mathrm{mg}$ per day), the steady-state blood Au concentration would be achieved at $3.5 \mu \mathrm{M}$ in a 12 -week treatment course $\mathrm{e}^{52}$. Although the action on other $\mathrm{Zn}$ enzymes and potential toxicity of auranofin and $\mathrm{Au}(\mathrm{I})$-based compounds are still need further investigation, considering its well-recorded safety in human, AUR as a dual inhibitor of MBLs and MCRs would largely broaden the therapeutic options in treating the infections caused by MCR-1 positive CRE.

Collectively, we have demonstrated that AUR acts synergistically with $\beta$-lactam antibiotics and COL on killing a broad spectrum of carbapenem- and/or COL-resistant strains, and slows down the development of $\beta$-lactam and COL resistance. Importantly, the in vitro antimicrobial potency of AUR and antibiotics could be well-translated in vivo. Our work clearly elucidates the antimicrobial action of the gold(I)-based drug and opens a horizon for the treatment of infections caused by superbugs carrying $b l a_{\mathrm{MBL}}$ and/or $m o r$ genes.

\section{Methods}

Chemicals and bacterial strains. Meropenem was purchased from TCI Chemicals (Shanghai, China). Kanamycin sulfate and Luria-Bertani (LB) broth powder were purchased from Affymetrix. Auranofin (AUR) was purchased from MedChemExpress (MCE, USA). The fluorescent substrate NBD-glycerol-3-PEA was purchased from Avanti Lipids, USA. TLC plate (Silica gel $60 \mathrm{~F}_{254}$, Aluminium sheets, $20 \times 20 \mathrm{~cm}$ ) was purchased from Merck, Germany. All the other chemicals were purchased from Sigma-Aldrich unless otherwise stated. All the sources of bacteria employed for cell-based and animal studies are listed in Supplementary Table 7. All the specific primers for different genes listed in Supplementary Table 8 were synthesized by BGI Gene Company (Shenzhen, China).

Initial screening of antimicrobial activity on antibiotics and different metals Metal salts used for the screening involved cobalt chloride ( $\mathrm{Co}(\mathrm{II})$ ), sodium trichloride ( $\mathrm{Sb}(\mathrm{III})$ ), nickel chloride ( $\mathrm{Ni}(\mathrm{II})$ ), arsenic trioxide (As(III)), copper sulfate $(\mathrm{Cu}(\mathrm{II})$ ), gold chloride $(\mathrm{Au}(\mathrm{I}))$, bismuth nitrate $(\mathrm{Bi}(\mathrm{III}))$. Briefly, overnight culture of $E$. coli CKE was performed 1:1000 dilution and regrew to mid-log phase, then diluted to $\mathrm{OD}_{600} 0.05-0.1$ in each well of 96-well plate. The bacterial suspension was exposed to the treatment of either COL $\left(1 \mu \mathrm{g} \cdot \mathrm{mL}^{-1}\right)$ or MER $\left(2 \mu \mathrm{g} \cdot \mathrm{mL}^{-1}\right)$ in the absence or presence of different metal ions at a fixed concentration $\left(50 \mu \mathrm{g} \cdot \mathrm{mL}^{-1}\right)$. The bacterial growth inhibition was examined by monitoring $\mathrm{OD}_{600}$ for $18 \mathrm{~h}$. Wells with no antibiotics or metal compounds served as growth controls and wells with LB medium served as background controls.

Construction of plasmids. Plasmids with full-length $m c r-1$ gene and truncated mcr-1 gene encoding soluble MCR-1 fragment (200-541aa, denoted as MCR-1-S) were from our own collection. The original genes were subcloned into pCR-XLTOPO and $\mathrm{pET}-15 \mathrm{~b}$ vectors via the SacI/BamHI and NdeI/BamHI restriction sites, respectively. Other $m c r$ genes were synthesized by BGI (China) and subcloned into pET-28a via NcoI/XhoI restriction sites, except for $m c r-6.1$ via NcoI/BamHI site. All the modified plasmids were constructed by using these plasmids as PCR template. PCR was performed using KOD Hot Start DNA polymerase (Novagen) based on the reaction conditions described in the protocol by the manufacturers. Digested fragments with full-length or truncated $\mathrm{mcr}-1$ were inserted into mutated pET-15b via the NdeI/BamHI restriction site for protein overexpression and thermal stability analysis. All the restriction enzymes and T4 ligase were purchased from New England Biolabs (UK) Ltd. Both gel extraction kits and plasmids extraction kits were purchased from QIAGEN. The constructed plasmids were subsequently transformed into E. coli DH5a competent cells for further molecular cloning. The full sequences of the plasmid were provided in Supplementary Data 1.

Protein purification. NDM-1, apo-NDM-1, NDM-1-C208A were overexpressed and purified according to the procedures described previously ${ }^{31}$. Briefly, a single colony of E. coli BL21 (DE3) (TIANGEN Biotech(Beijing)Co., Ltd.) transformed with the plasmid encoding NDM-1 or its variant was inoculated into LB medium supplied with $50 \mu \mathrm{g} \cdot \mathrm{mL}^{-1}$ kanamycin and grown at $37^{\circ} \mathrm{C}$. Protein overexpression was induced using $0.2 \mathrm{mM}$ isopropy- $\beta$-D-thiogalactoside (IPTG) supplemented with $0.2 \mathrm{mM} \mathrm{ZnSO}_{4}$ at $\mathrm{OD}_{600} 0.6$. The bacterial culture was incubated at $25^{\circ} \mathrm{C}$ overnight. To purify the respective protein, the cultured cells were harvested by centrifugation at $4500 \times g$ and resuspended in a lysis buffer $(20 \mathrm{mM}$ HEPES, $0.5 \mathrm{M}$ $\mathrm{NaCl}$, and $1 \mathrm{mM}$ PMSF at $\mathrm{pH} 7.0$ ). The cells were ice-cooled and lysed by sonication and then centrifuged at $20,000 \times g$ for $30 \mathrm{~min}$ to remove the majority of cell debris The supernatant was filtered using Minisart syringe filter $(0.45 \mu \mathrm{m})$ to remove any remaining large and insoluble cell debris, and was then applied to a $5 \mathrm{~mL} \mathrm{Ni(II)-}$ loaded HiTrap chelating columns (GE Healthcare) at a rate of $2 \mathrm{~mL} \cdot \mathrm{min}^{-1}$. The column was washed using five column volumes of washing buffer $(20 \mathrm{mM}$ HEPES, $0.5 \mathrm{M} \mathrm{NaCl}$, and $30 \mathrm{mM}$ imidazole at $\mathrm{pH} 7.0$ ). The protein was eluted out using four column volumes of the same buffer with gradient. amounts of imidazole, and was subsequently dialyzed against the cleavage buffer $(20 \mathrm{mM}$ HEPES, $0.15 \mathrm{M} \mathrm{NaCl}$ at $\mathrm{pH}$ 7.0). The N-terminal His-tag of the fusion protein was cleaved by adding 50 $\mathrm{NIH}$ units of thrombin (Sigma-Aldrich, USA) at $25^{\circ} \mathrm{C}$ for $3 \mathrm{~h}$ with mild shaking and the cleaved His-tag was separated from the resulting proteins by passing through the Ni(II)-NTA column again using washing buffer so that $>90 \%$ of the proteins were in the flow-through fraction. The enzymes were further purified using HiLoad 16/60 Superdex 200 pg gel filtration column (GE Healthcare). The samples were then concentrated using Amicon Ultra-15 Centrifugal Filter Devices (Milli pore) and separated into aliquots after dialysis with storage buffer (20 mM HEPES $0.1 \mathrm{M} \mathrm{NaCl}$ at $\mathrm{pH} 7.0$ ) for long-term storage at $-80^{\circ} \mathrm{C}$. For the purification of MCR proteins, a single colony of E. coli BL21(DE3) transformed with the plasmid encoding MCR-1 or MCR-1-S was inoculated into LB medium supplied with 100 $\mu \mathrm{g} \cdot \mathrm{mL}^{-1}$ ampicillin, and cultured at $37^{\circ} \mathrm{C}$ overnight. Overnight cultures were 1:1000 amplified with fresh LB medium supplemented with $100 \mu \mathrm{g} \cdot \mathrm{mL}^{-1}$ ampicillin Bacterial cultures were supplemented with $0.2 \mathrm{mM}$ IPTG at $\mathrm{OD}_{600}$ of 0.6 , and subsequently, cultured at $25^{\circ} \mathrm{C}$ for another $20 \mathrm{~h}$. Cell pellets were collected by centrifugation at $4,500 \times g$ for $30 \mathrm{~min}$ at $4{ }^{\circ} \mathrm{C}$, and lysed by sonication in lysis buffer (20 mM HEPES, $50 \mathrm{mM} \mathrm{NaCl}, 20 \mathrm{mM}$ imidazole at $\mathrm{pH} 7.4$ ) at $4{ }^{\circ} \mathrm{C}$ and centrifuged to remove the majority of cell debris. The supernatant was collected by centrifuge at $18,000 \times g$ at $4{ }^{\circ} \mathrm{C}$ for $45 \mathrm{~min}$ and filtered using Minisart syringe filter $(0.45 \mu \mathrm{m})$ to remove remaining insoluble cell debris. The lysate was subjected to a $5 \mathrm{ml} \mathrm{Ni(II)-}$ loaded HiTrap chelating columns pre-washed by five column volumes of washing buffer (20 mM HEPES, $500 \mathrm{mM} \mathrm{NaCl}$, and $30 \mathrm{mM}$ imidazole at $\mathrm{pH}$ 7.4) at a rate of $2 \mathrm{~mL} \cdot \mathrm{min}^{-1}$. The protein was eluted out using five column volumes of the washing buffer with gradient amounts of imidazole, and was subsequently incubated with 50 $\mathrm{NIH}$ units of thrombin for the following dialysis in cleavage buffer $(20 \mathrm{mM}$ HEPES 
$10 \mathrm{mM} \mathrm{NaCl}$ at $\mathrm{pH} 7.4)$ at $4{ }^{\circ} \mathrm{C}$ overnight. The protein was reloaded onto another $\mathrm{Ni}(\mathrm{II})-\mathrm{NTA}$ column to collect the flow-through fraction. Q-HP column (GE Healthcare) was employed for further purification, where gradient amounts of $\mathrm{NaCl}$ $(10-500 \mathrm{mM})$ were used to elute protein sample. Target fractions were concentrated and loaded onto Superdex 75 (GE Healthcare) equilibrated with running buffer (20 $\mathrm{mM}$ HEPES, $50 \mathrm{mM} \mathrm{NH}_{4} \mathrm{NO}_{3}, \mathrm{pH}=7.4$ ). For the purification of full-length MCR-1 protein, an additional centrifugation at $80,000 \times g$ was performed to collect the insoluble membrane portion after the removal of cell debris. The resulting membrane protein was solubilized in PBS buffer supplemented with $2 \%(w / v) n$-Dodecyl $\beta$-D-maltoside at $4{ }^{\circ} \mathrm{C}$ overnight. All other related buffers were similar to those for MCR-1-S purification but supplemented with $0.023 \%$ (w/v) DDM. For the preparation of apo-MCR-1-S, purified MCR-1-S was exposed to 50 molar equivalents of EDTA at $4{ }^{\circ} \mathrm{C}$ overnight and then concentrated to $1 \mathrm{mg} \cdot \mathrm{mL}^{-1}$. The protein was then extensively dialysis against a buffer (20 mM HEPES, $\left.\mathrm{pH} 7.4,50 \mathrm{mM} \mathrm{NH}_{4} \mathrm{NO}_{3}\right)$ at $4^{\circ} \mathrm{C}$ for $24 \mathrm{~h}$.

NDM-1 activity assay. The NDM-1 activity assay was performed based on a previous reported method ${ }^{34}$. Briefly, NDM-1 or NDM-1-C208A $(50 \mathrm{nM})$ were incubated with $\mathrm{Au}\left(\mathrm{PEt}_{3}\right) \mathrm{Cl}$ in enzyme assay buffer $[50 \mathrm{mM}$ HEPES buffer, $100 \mathrm{mM}$ $\mathrm{NaCl}$ at $\mathrm{pH} 7.4$ ] for $1 \mathrm{~h}$ at $25^{\circ} \mathrm{C}$, and then mixed with equal volume of $200 \mu \mathrm{M}$ nitrocefin. The assay was performed in 96-well plate using the kinetic mode on a Varian Cary $50 \mathrm{UV}$-visible spectrophotometer at $25^{\circ} \mathrm{C}$. The increase in absorbance at $490 \mathrm{~nm}$ was monitored every minute for a duration of $30 \mathrm{~min}$ until the reaction was completed. Linear portions of curves were used for data analysis. For the timedependent incubation assay, NDM-1 $(10 \mathrm{nM})$ were preincubated with $\mathrm{Au}\left(\mathrm{PEt}_{3}\right) \mathrm{Cl}$ $(5 \mu \mathrm{M})$ for different time from 0 to $90 \mathrm{~min}$, followed by the enzyme activity measurement using the method mentioned above.

Michaelis-menten kinetics. NDM- 1 enzyme $(50 \mathrm{nM})$ was incubated with $\mathrm{Au}$ $\left(\mathrm{PEt}_{3}\right) \mathrm{Cl}$ at various concentrations $(0,0.5,1$, and $2 \mu \mathrm{M})$ in enzyme assay buffer for $1 \mathrm{~h}$ at $25^{\circ} \mathrm{C}$. Nitrocefin as a substrate was added to the enzyme to make the final substrate concentrations from 25 to $200 \mu \mathrm{M}$. Control experiment was also performed in the absence of inhibitors under the same conditions. The $K_{\mathrm{m}}, V_{\max }$, and $K i$ for both the uninhibited and inhibited reactions were obtained by fitting the data into the double reciprocal Lineweaver-Burk plots.

Zinc displacement analysis. The purified NDM-1 $(10 \mu \mathrm{M})$ or MCR-1-S $(20 \mu \mathrm{M})$ was incubated with $50 \mu \mathrm{M} \mathrm{ZnSO}$ or $100 \mu \mathrm{M}$ zinc acetate $\left(\mathrm{Zn}(\mathrm{Ac})_{2}\right)$ in dialysis buffer [50 mM HEPES, $20 \mathrm{mM}$ at $\mathrm{pH} 7.4$ ] overnight at $4{ }^{\circ} \mathrm{C}$, and the unbound $\mathrm{Zn}$ (II) ions were removed by dialysis in $\mathrm{Zn}$-free dialysis buffer to ensure that $\mathrm{Zn}(\mathrm{II})$ was fully loaded into the proteins. The NDM-1 or MCR-1-S was then incubated with various concentrations of $\mathrm{Au}\left(\mathrm{PEt}_{3}\right) \mathrm{Cl}$ by dialysis at $4{ }^{\circ} \mathrm{C}$ overnight with mild shaking. The samples were subsequently dialyzed in dialysis buffer to remove unbound-metal ions, and were then acidified by concentrated $\mathrm{HNO}_{3}$ at $60^{\circ} \mathrm{C}$ for $4 \mathrm{~h}$. Samples were diluted to a detectable concentration range and subjected to ICPMS analysis (Agilent 7700x, Agilent Technologies, CA, USA) with ${ }^{115} \mathrm{In}$ as an

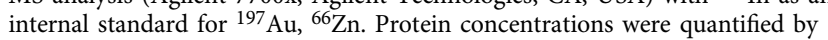
standard bicinchoninic acid (BCA) assay (Thermal Fisher Scientific, USA). The data were fitted by one-site binding Hill plot, and the maximal binding capacity $\left(\mathrm{B}_{\max }\right)$ as well as the dissociation constant $\left(K_{\mathrm{d}}\right)$ were estimated.

Zinc supplementation assay. Au-NDM-1 or Au-MCR-1-S was prepared by incubation of apo-proteins with excess amounts of $\mathrm{Au}\left(\mathrm{PEt}_{3}\right) \mathrm{Cl}$ or AuCl overnight, followed by removal of unbound $\mathrm{Au}(\mathrm{I})$ and verification of the bound $\mathrm{Au}$ by ICPMS. The above protein solutions were mixed with $\mathrm{ZnSO}_{4}$ or with $\mathrm{Zn}(\mathrm{Ac})_{2}$ at concentrations up to 50 molar equivalents for NDM- 1 or 5 molar equivalents for MCR-1-S, and incubated for $4 \mathrm{~h}$ at $25^{\circ} \mathrm{C}$. Nitrocefin was added to the protein $(50 \mathrm{nM})$ solutions and reaction rate was calculated as mentioned above.

Zinc release assay. Zinc release assay was carried out with a metallochromic indicator 4-(2-pyridylazo)resorcinol (PAR) based on a modified method as described previously ${ }^{55}$. Briefly, for PAR assay on NDM-1, Zn $\mathrm{n}_{2}-\mathrm{NDM}-1(10 \mu \mathrm{M}$ protein in $20 \mathrm{mM}$ HEPES buffer, $\mathrm{pH} 7.4,150 \mathrm{mM} \mathrm{NaCl}$ ) was incubated with 20 molar equivalents of $\mathrm{Au}\left(\mathrm{PEt}_{3}\right) \mathrm{Cl}$, for different time periods at $25^{\circ} \mathrm{C}$. The mixtures were then incubated with $150 \mu \mathrm{M}$ (4-(2-pyridylazo) resorcinol (PAR) and UV spectra were then recorded. The absorbance at $490 \mathrm{~nm}$ is due to the formation of $\mathrm{Zn}(\mathrm{PAR})_{2}$. $\mathrm{Zn}$ (II) contents were quantified in accordance with the standards. For PAR assay on MCR-1-S, all the procedures were similar except that MCR-1-S protein at $20 \mu \mathrm{M}$ and $\mathrm{Au}\left(\mathrm{PEt}_{3}\right) \mathrm{Cl}$ at 10 molar equivalents were used.

MALDI-TOF mass spectrometry. The binding of AUR to NDM-1 was examined by matrix assisted laser ionization time of flight mass spectrometry (MALDI-TOF MS) (Bruker ultraflex extreme MALDI-TOF-TOF-MS). NDM-1 protein was incubated with 10 molar equivalents of AUR at $4{ }^{\circ} \mathrm{C}$ for $12 \mathrm{~h}$. One microliter of the protein sample was mounted on a modified stainless-steel sample plate using electrically conductive tapes (9713 XYZ-Axis; 3 M, St. Paul, MN) and then overlaid with $1 \mu \mathrm{L}$ of matrix solution (saturated sinapic acid in $\mathrm{ACN}$ : $\mathrm{H}_{2} \mathrm{O}=50$ : 50 ). The plate was then introduced into the mass spectrometer, operating in the positive reflectron mode. The mass resolution of ion peaks was recorded in the range of $\mathrm{m} / \mathrm{z}$ 20,000-40,000. MS data were processed using FlexAnalysis (version 1.2, Bruker Daltonics).

X-ray crystallography. Au-NDM-1 crystals were obtained by co-crystallization. Au-NDM-1 was prepared by incubating apo-NDM-1 with 10 eq. of AUR overnight at $25^{\circ} \mathrm{C}$ and then remove the excess $\mathrm{Au}(\mathrm{I})$ by dialysis. Crystals of the Au-NDM-1 were grown by sitting-drop vapor diffusion method with the precipitant containing $100 \mathrm{mM}$ MES (pH 5.5), $200 \mathrm{mM}$ lithium sulfate, and 25\% PEG 3350 (w/v). Tetragonal or diamond-like crystals appeared in 1 week and grew up to full size after two weeks. These crystals generally diffracted to the resolution ranging from 1.09 to $1.40 \AA$. The crystals were soaked in cryo-protectant solution [100 mM MES (pH 5.5), $200 \mathrm{mM}$ lithium sulfate, $25 \%$ PEG 3350 (w/v), and 15\% glycerol (w/v)] before frozen into liquid nitrogen. Au-MCR-1-S crystals were obtained by a soaking method according to a modified method as reported previous ${ }^{31}$. Crystal screening (sitting drop) was performed by mixing equal volume of the protein and reservoir solution (100 mM KSCN, 30-32\% PEG 3350, $100 \mathrm{mM}$ Tris- $\mathrm{HNO}_{3}$, $\mathrm{pH}$ 8.0). Crystals of native Zn-bound MCR-1-S appeared at $25^{\circ} \mathrm{C}$ after two weeks. The crystals were transferred into wells supplemented with chelating solution $(10 \mathrm{mM}$ EDTA, 32\% PEG 3350, 100 mM Tris-HNO 3 , pH 8.0). Apo-MCR-1-S crystals were obtained after 12-h treatment, and washed three times with washing solution $(32 \%$

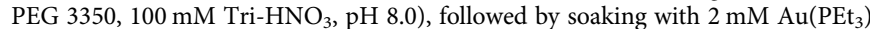
$\mathrm{Cl}$ in soaking solution (32\% PEG 3350, 25\% glycerol, $100 \mathrm{mM} \mathrm{Tri-} \mathrm{HNO}_{3}, \mathrm{pH} 8.0$ ) in darkness. The crystals were collected two weeks later and flash-frozen in liquid nitrogen.

All the diffraction data were collected at BL17U beamline of Shanghai Synchrotron Radiation Facility (SSRF) at the wavelengths of $0.979 \AA$. The presence of gold was confirmed by $m F o-D F c$ (difference Fourier) map with positive peaks (Au-NDM-1: $\geq 40 \sigma$, Au-MCR-1-S: $\geq 30 \sigma$ ) and anomalous peaks (Au-NDM-1: $\geq 45 \sigma$, Au-MCR-1-S: $\geq 18 \sigma$ ) corresponding to gold sites as well as X-ray excitation spectrum with an excitation peak for gold (Au-L3) at the radiation energy around $9.8 \mathrm{keV}$ (Supplementary Fig. 6a and 8). The diffraction data were reduced with XDS $^{56}$. The Phaser from CCP4 suite $\mathrm{e}^{57,58}$ and Phenix ${ }^{59}$ were used for data refinement and finalization. Native NDM-1 structure (PDB ID: 5ZGE) ${ }^{23}$ was used as a searching model for molecular replacement of Au-NDM-1 while the Cterminal catalytic domain of MCR-1 (PDB ID: 5GRR ${ }^{60}$ was used for that of AuMCR-1-S. Cycles of refinement with the anomalous data and with careful manual rebuilding were done by using Refmac $5.8 .0135^{61}$ and Coot version $6^{62}$, respectively. TLS refinement was used in the later stages of data processing. The Au occupancy was refined according to Au anomalous signal and was assessed based on atomic B-factor. The final models were analyzed with MolProbity $4.4^{63}$. Structural alignment was done over $\mathrm{C}_{\alpha}$ residues using DaliLite version 5. All of the structural illustrations were generated using the software PyMOL1.8.0.0. The coordinates and structure factors for Au-NDM-1, Au-MCR-1-S, Zn-MCR-1-S, and Apo-MCR-1-S were deposited at protein databank with accessing code 6HLE, 6LI6 6LI4, and 6LI5, respectively. Details of the data collection and model refinement statistics are summarized in Supplementary Tables 1, 2, 4 and 5.

Cellular thermal shift assay (CETSA). The cellular thermal shift assay was performed according to a general standard method ${ }^{36}$. Bacterial cultures (NDM-Rosetta or MCR-1-S-BL21) at logarithmic phase were exposed to AUR $\left(12 \mu \mathrm{g} \cdot \mathrm{mL}^{-1}\right.$ for NDM-Rosetta, $15 \mu \mathrm{g} \cdot \mathrm{mL}^{-1}$ for MCR-1-S-BL21) treatment overnight. The bacterial pellets were harvested and washed with PBS for three times. The cell suspensions were aliquoted into PCR tubes and heat treatment was performed at the designated temperature for $3 \mathrm{~min}$ in a 96-well thermal cycler. The tubes were cooled immediately at $25^{\circ} \mathrm{C}$, and the heat treatments were repeated for three cycles. For the cell lysis, the samples were frozen-thawed in liquid nitrogen and thermal cycler was set at $25^{\circ} \mathrm{C}$. The samples were vortexed gently after each cycle and centrifuged at $20,000 \times g$ to obtain the supernatant. All the samples were subjected to SDS-PAGE gel and electrotransferred to a PVDF membrane (Hybond-P, GE Healthcare). A PageRuler Prestained Protein Ladder \#26616 (Thermo) was used as a standard marker. Diluted protein primary antibody [NDM-1 monoclonal antibody (NBP177688, NOVUS Biologicals)] or MCR-1 polyclonal antibody (CSBPA745804LA01ENL, Cusabio Technology LLC) and the secondary antibody (Antirabbit IgG, HRP-linked Antibody, \#7074, Cell Signaling Technology, Inc.) were applied after the standard blotting procedures. The protein bands were calorimetrically developed with specified ratio of substrates comprising nitroblue tetrazolium/5-bromo-4-chloro-3-indolyl phosphate (NBT/BCIP) for $15 \mathrm{~min}$. Image J $(1.52 \mathrm{a})^{64}$ was used to quantify the signals of each band for analysis. The software GraphPad Prism 8.0 (GraphPad Software, La Jolla CA, USA, www.graphpad.com) was used to analyze the resulting plots. Full scans of the blots were provided in Supplementary Data 2.

Lysate activity assay. Overnight cultures of NDM-Rosetta were diluted to $\mathrm{OD}_{600}$ $\sim 0.5$ with fresh $\mathrm{LB}$ medium supplemented with $\mathrm{AUR}$ or $\mathrm{Au}\left(\mathrm{PEt}_{3}\right) \mathrm{Cl}$ at varying concentrations. The bacterial pellets were collected by centrifuge and washed with PBS for four times, followed by lysis via sonication in lysis buffer $(20 \mathrm{mM}$ HEPES, $50 \mathrm{mM} \mathrm{NaCl}, 2 \mathrm{mM}$ TCEP at $\mathrm{pH}$ 7.4). The total protein concentrations of the lysate 
were normalized to $1 \mathrm{mg} \cdot \mathrm{mL}^{-1}$ by BCA assay and subsequently subjected to activity assay as described in NDM-1 activity assay section.

MCR-1 activity assay. The enzymatic assay was performed according to a previous reported method with a slight modification ${ }^{38}$. Briefly, $0.1 \mathrm{mM}$ full-length MCR-1 was treated with 10 molar equivalents of $\mathrm{AuCl}$ or $\mathrm{Au}\left(\mathrm{PEt}_{3}\right) \mathrm{Cl}$ at $25^{\circ} \mathrm{C}$ for $18 \mathrm{~h}$ and subsequently incubated with $0.1 \mathrm{mM}$ of a fluorescent substrate, nitrobenzodiazolelabeled glycerol-3-phosphoethanolamine (NBD-glycerol-3-PEA, Avanti Lipids, USA) in assay buffer (50 mM HEPES, pH 7.5, $100 \mathrm{mM} \mathrm{NaAc}, 0.023 \%$ DDM) at $25^{\circ} \mathrm{C}$ overnight. TLC plate was used to separate NBD-glycerol from the MCR-1 reaction mixture in a mobile phase [ethyl acetate: methanol: water, 7:2:1 (vol/vol)] The reaction product was analyzed by exposing the TLC plate to UV light (455$485 \mathrm{~nm}$ ) and visualizing the fluorescent signals with a gel imaging system.

Microdilution MIC assay. Generally, bacteria were cultured in LB broth overnight at $37^{\circ} \mathrm{C}, 250 \mathrm{rpm}$. The bacterial density was adjusted to about $1 \times 10^{6} \mathrm{CFU} \cdot \mathrm{mL}^{-1}$ and checked by CFU counting on agar plates afterwards. Tested antibiotics (MER or COL) or AUR or their combinations were added triplicately into individual wells of flat-bottomed 96-well plate and performed 2-fold serial dilution, followed by addition of prepared bacterial inocula. The plate was then incubated at $37^{\circ} \mathrm{C}$ overnight. Wells with no drugs served as growth controls and wells with medium only served as background controls. The MIC was determined as the lowest concentration of a drug that could inhibit the growth of microorganism by both visual reading and $\mathrm{OD}_{600}$ using a microtiter plate reader.

The FICI was determined according to the following equation: $\mathrm{FICI}=\mathrm{FIC}_{\mathrm{A}}+$ $\mathrm{FIC}_{\mathrm{B}}=\mathrm{C}_{\mathrm{A}} / \mathrm{MIC}_{\mathrm{A}}+\mathrm{C}_{\mathrm{B}} / \mathrm{MIC}_{\mathrm{B}}$, where $\mathrm{MIC}_{\mathrm{A}}$ and $\mathrm{MIC}_{\mathrm{B}}$ are the MIC values of compounds $A$ and $B$, respectively, when functioning alone, and $C_{A}$ and $C_{B}$ are the concentrations of compounds $\mathrm{A}$ and $\mathrm{B}$ at the effective combinations. Synergism was defined when FICI $\leq 0.5$, indifference was defined when FICI $>0.5$ and $<4$, and antagonism was defined when FICI $\geq 4$. All of the determinations were performed at least in triplicate on different days.

Time-kill assay. In a typical assay, bacteria (NDM-HK or MCR-1-J53) were cultured overnight and diluted 1:100 into $\mathrm{LB}$ broth at $37^{\circ} \mathrm{C}$ for $3 \mathrm{~h}$ to reach $\log$ phase. The initial bacterial density was adjusted to $\sim 10^{5}-10^{6} \mathrm{CFU} \cdot \mathrm{mL}^{-1}$ and then exposed to antibiotic, gold compounds either alone or in combination. LB broth with no drugs served as a control. Aliquots of bacterial suspension were withdrawn at different time intervals during $24 \mathrm{~h}$ for inspection of bacterial viability by agar plating. The concentrations of the drugs used were $16 \mu \mathrm{g} \cdot \mathrm{mL}^{-1} \mathrm{MER}$ and $30 \mu \mathrm{g} \cdot \mathrm{mL}^{-1}$ AUR for NDM-1 assay and $2 \mu \mathrm{g} \cdot \mathrm{mL}^{-1}$ COL and $6 \mu \mathrm{g} \cdot \mathrm{mL}^{-1}$ AUR for MCR-1 assay. Data from three independent experiments were averaged and plotted as $\log _{10} \mathrm{CFU} \cdot \mathrm{mL}^{-1}$ versus time (h) for each time point over $24 \mathrm{~h}$. All assays were triplicated and performed three times on different days.

Membrane potential assay. Membrane potential assay was carried out based on a modified method as previously described ${ }^{40}$ and the manufacturer's instructions of BacLight bacterial membrane potential kit (B34950, Thermo fisher). Briefly, about $10^{6} \mathrm{CFU}$ mid-log phase bacterial pellets (S. flexneri (MCR-1 ${ }^{+}$) or S. flexneri (MCR$\left.\left.1^{-}\right)\right)$that were preincubated with AUR $(3 \mu \mathrm{M}), \mathrm{Au}\left(\mathrm{PEt}_{3}\right) \mathrm{Cl}(3 \mu \mathrm{M})$ or CCCP $(5 \mu \mathrm{M})$ at fixed concentration, were collected, and washed by PBS for three times. The bacterial pellets were then resuspended in PBS supplemented with DiOC2 $(30 \mu \mathrm{M})$ and stained at $37^{\circ} \mathrm{C}$ for $30 \mathrm{~min}$. Stained bacteria were then assayed in a flow cytometer and the signals from FITC-A ( $488 \mathrm{~nm}$, green gate) and PI-A $(633 \mathrm{~nm}$, red gate) were collected and then analyzed by FlowJo v10 (Tree Star Inc., Ashland, USA). S. flexneri without treatment served as the control. The assays were performed in triplicate, repeated three times and results were expressed with fluorescence ratio (green/red) as average \pm SD

Resistance study. Briefly, bacteria (NDM-HK or MCR-1-J53) at $\sim 1 \times 10^{10} \mathrm{CFU}$ was plated onto LB agar containing antibiotics (MER or COL) and AUR at different concentrations, and incubated at $37^{\circ} \mathrm{C}$. After incubation for $48 \mathrm{~h}$, to any plates with observable colonies, up to four colonies were picked and recultured, followed by the measurement of their MIC values. Any MIC that was greater than the original value was determined as higher-level resistant mutant colony. The concentration that restricted the growth of mutant colonies was determined as MPC. At the identical experiment, the higher-level resistant mutant colonies were enumerated. The relative mutation frequency for each MIC for each strain/antibiotic pair was calculated as the proportion of resistant colonies per inoculum. The serial passage assay was performed by a method described previously ${ }^{31}$. Briefly, an overnight culture of bacteria (NDM-HK or MCR-1-J53) was diluted to $\sim 10^{7}$ CFU. $\mathrm{mL}^{-1}$ in LB broth. The as-diluted bacterial suspension was added to each well of 96-well plate supplemented with drugs at escalating concentrations. All the plates were incubated at $37^{\circ} \mathrm{C}$ and the growth of cultures was checked at 24-h intervals. Cultures from the second highest concentrations that allowed growth were performed 1:1000 dilution into fresh medium supplemented with the same concentrations of drugs. For MER, 1 fold of MIC was set as $16 \mu \mathrm{g} \cdot \mathrm{mL}^{-1}$. For the combination of MER and AUR, 1 fold of MIC was set as $2 \mu \mathrm{g} \cdot \mathrm{mL}^{-1} \mathrm{MER}+$ $8 \mu \mathrm{g} \cdot \mathrm{mL}^{-1}$ AUR. For COL, 1 fold of MIC was set as $8 \mu \mathrm{g} \cdot \mathrm{mL}^{-1}$. For the combination of COL and AUR, fold of MIC was set as $2 \mu \mathrm{g} \cdot \mathrm{mL}^{-1} \mathrm{COL}+5 \mu \mathrm{g} \cdot \mathrm{mL}^{-1}$
AUR. This in vitro passage was repeated for 16 days. MIC of MER was determined every two passages.

Ethics statement. The ethics Committee on the Use of Live Animals in Teaching \& Research (CULATR) of the University of Hong Kong (HKU) approved all of the protocols (Reference code: 4008-16 and 5079-19) and procedures in this study.

Animals: Six to eight weeks old, female, $18-22 \mathrm{~g}$ of weight $\mathrm{Balb} / \mathrm{c}$ mice were purchased from Charles River Laboratories, Inc. and used in all mouse studies. The animals were numbered and allocated into groups using a simple randomization of excel-generated random numbers. To avoid biases, we also assured that different treatments were performed on the same day. All the animals were randomized to cages for each experiment and had free access to food and water.

Murine peritonitis infection. The murine infection experiments were modified according to previously described methods ${ }^{8}$. For the bacterial load experiment, an overnight culture of $K$. pneumoniae $9607\left(\mathrm{MCR}-1^{+}\right)$was performed 1:250 dilution in $\mathrm{LB}$ broth and regrew to about $\mathrm{OD}_{600} 0.5$ at $37^{\circ} \mathrm{C}, 250 \mathrm{rpm}$. Bacterial pellets were collected and washed by PBS buffer three times for further use. Mice were infected intraperitoneally (i.p.) with a dose of $2 \times 10^{6} \mathrm{CFU}$ of bacteria in PBS. Four groups of mice were i.p. administered 1-h post-infection with single dose of vehicle, COL $\left(2 \mathrm{mg} \cdot \mathrm{kg}^{-1}\right)$, AUR $\left(0.5 \mathrm{mg} \cdot \mathrm{kg}^{-1}\right)$, or their combination therapy $(n=4)$. All the mice were scarified at $48 \mathrm{~h}$ following systemic infection, and bacterial loads in livers and spleens were examined by agar plating. For survival assay, all the operations of infection were similar, except that infection was induced by E. coli CKE at $5 \times 10^{6}$ CFU per mice in the presence of $2 \%$ mucin, and single dose of vehicle, AUR $\left(0.25 \mathrm{mg} \cdot \mathrm{kg}^{-1}\right)$, COL $\left(1 \mathrm{mg} \cdot \mathrm{kg}^{-1}\right)$ and their combination was i.p. injected to the infected mice 0.5 -h post-infection $(n=6)$. Body weights and mice survival were monitored till endpoint of the experiment.

Statistical analysis. All statistical analyses were performed on three independent experiments, or more if otherwise stated, using Prism 8.0 (GraphPad Software Inc.) software. Sample size and information about statistical tests are reported in the figure legends and Methods. Data are presented as mean \pm SEM.

Reporting summary. Further information on research design is available in the Nature Research Reporting Summary linked to this article.

\section{Data availability}

The protein crystal structure data for Au-NDM-1, Zn-NDM-1, Au-MCR-1-S, Zn-MCR 1-S, and apo-MCR-1-S have been deposited at Protein Data Bank (PDB) with accessing codes of $6 \mathrm{LHE}, 5 \mathrm{ZGE}, 6 \mathrm{LI} 6,6 \mathrm{LI} 4$, and 6LI5, respectively. All other data supporting the findings of this study are available from the corresponding author (Hongzhe Sun: hsun@hku.hk) on request. Source data are provided with this paper.

Received: 16 April 2020; Accepted: 17 September 2020; Published online: 16 October 2020

\section{References}

1. Andersson, D. I. \& Hughes, D. Antibiotic resistance and its cost: is it possible to reverse resistance? Nat. Rev. Microbiol. 8, 260-271 (2010).

2. Kumarasamy, K. K. et al. Emergence of a new antibiotic resistance mechanism in India, Pakistan, and the UK: a molecular, biological, and epidemiological study. Lancet Infect. Dis. 10, 597-602 (2010).

3. Rolain, J. M., Parola, P. \& Cornaglia, G. New Delhi metallo-beta-lactamase (NDM-1): towards a new pandemia? Clin. Microbiol. Infect. 16, 1699-1701 (2010)

4. López, C., Ayala, J. A., Bonomo, R. A., González, L. J. \& Vila, A. J. Protein determinants of dissemination and host specificity of metallo- $\beta$-lactamases. Nat. Commun. 10, 3617 (2019).

5. Gupta, N., Limbago, B. M., Patel, J. B. \& Kallen, A. J. Carbapenem-resistant Enterobacteriaceae: epidemiology and prevention. Clin. Infect. Dis. 53, 60-67 (2011)

6. Patrice, N., Thierry, N. \& Laurent, P. Global spread of carbapenemaseproducing Enterobacteriaceae. Emerg. Infect. Dis. 17, 1791 (2011).

7. Bush, K. \& Macielag, M. J. New beta-lactam antibiotics and beta-lactamase inhibitors. Expert Opin. Ther. Pat. 20, 1277-1293 (2010).

8. Nordmann, P., Dortet, L. \& Poirel, L. Carbapenem resistance in Enterobacteriaceae: here is the storm! Trends Mol. Med. 18, 263-272 (2012).

9. Guh, A. Y. et al. Epidemiology of carbapenem-resistant Enterobacteriaceae in 7 US communities, 2012-2013. JAMA 314, 1479-1487 (2015).

10. Newton, B. A. The properties and mode of action of the polymyxins. Bacteriol. Rev. 20, 14-27 (1956) 
11. Liu, Y. Y. et al. Emergence of plasmid-mediated colistin resistance mechanism MCR-1 in animals and human beings in China: a microbiological and molecular biological study. Lancet Infect. Dis. 16, 161-168 (2016).

12. Gunn, J. S. The Salmonella PmrAB regulon: lipopolysaccharide modifications, antimicrobial peptide resistance and more. Trends Microbiol. 16, 284-290 (2008).

13. Wang, C. et al. Identification of novel mobile colistin resistance gene mcr-10. Emerg. Microbes Infect. 9, 508-516 (2020).

14. Wang, R. et al. The global distribution and spread of the mobilized colistin resistance gene mcr-1. Nat. Commun. 9, 1179 (2018).

15. Sherman, E. X., Hufnagel, D. A. \& Weiss, D. S. MCR-1 confers crossresistance to lysozyme. Lancet Infect. Dis. 16, 1226-1227 (2016).

16. Hernández, M. et al. Co-occurrence of colistin-resistance genes mcr-1 and mcr-3 among multidrug-resistant Escherichia coli isolated from cattle, Spain, September 2015. Eur. Surveill. 22, 30586 (2017).

17. Fukuda, A. et al. High prevalence of mcr-1, mcr-3 and mcr-5 in Escherichia coli derived from diseased pigs in Japan. Int. J. Antimicrob. Agents 51, 163-164 (2018).

18. Delgado-Blas, J. F., Ovejero, C. M., Abadia-Patiño, L. \& Gonzalez-Zorn, B. Coexistence of mcr-1 and bla $a_{\mathrm{NDM}-1}$ in Escherichia coli from Venezuela. Antimicrob. Agents Chemother. 60, 6356 (2016).

19. Sun, J. et al. Co-transfer of $b l a_{\mathrm{NDM}-5}$ and mcr-1 by an IncX3-X4 hybrid plasmid in Escherichia coli. Nat. Microbiol. 1, 16176 (2016).

20. Yao, X., Doi, Y., Zeng, L., Lv, L. \& Liu, J.-H. Carbapenem-resistant and colistin-resistant Escherichia coli co-producing NDM-9 and MCR-1. Lancet Infect. Dis. 16, 288-289 (2016).

21. Wang, Y. et al. Comprehensive resistome analysis reveals the prevalence of NDM and MCR-1 in Chinese poultry production. Nat. Microbiol. 2, 16260 (2017).

22. Liu, L., Feng, Y., Zhang, X., McNally, A. \& Zong, Z. New variant of mcr-3 in an extensively drug-resistant Escherichia coli clinical isolate carrying mcr-1 and bla ${ }_{\mathrm{NDM}-5}$. Antimicrob. Agents Chemother. 61, e01757-01717 (2017).

23. Zhang, H. \& Hao, Q. Crystal structure of NDM-1 reveals a common $\beta$-lactam hydrolysis mechanism. FASEB J. 25, 2574-2582 (2011).

24. Feng, H. et al. The mechanism of NDM-1-catalyzed carbapenem hydrolysis is distinct from that of penicillin or cephalosporin hydrolysis. Nat. Commun. 8, 2242 (2017)

25. González, L. J. et al. Membrane anchoring stabilizes and favors secretion of New Delhi metallo- $\beta$-lactamase. Nat. Chem. Biol. 12, 516-522 (2016).

26. Wang, Y. et al. Prevalence, risk factors, outcomes, and molecular epidemiology of mcr-1-positive Enterobacteriaceae in patients and healthy adults from China: an epidemiological and clinical study. Lancet Infect. Dis. 17, 390-399 (2017).

27. Hinchliffe, P. et al. Insights into the mechanistic basis of plasmid-mediated colistin resistance from crystal structures of the catalytic domain of MCR-1. Sci. Rep. 7, 39392 (2017)

28. Stojanoski, V. et al. Structure of the catalytic domain of the colistin resistance enzyme MCR-1. BMC Biol. 14, 81 (2016).

29. $\mathrm{Hu}, \mathrm{M}$. et al. Crystal structure of Escherichia coli originated MCR-1, a phosphoethanolamine transferase for colistin resistance. Sci. Rep. 6, 38793 (2016).

30. Li, H. et al. Molecular insights into functional differences between mcr-3- and mcr-1-mediated colistin resistance. Antimicrob. Agents Chemother. 62, e00366-18 (2018).

31. Wang, R. et al. Bismuth antimicrobial drugs serve as broad-spectrum metallobeta-lactamase inhibitors. Nat. Commun. 9, 439 (2018).

32. Roder, C. \& Thomson, M. J. Auranofin: repurposing an old drug for a golden new age. Drugs R. D. 15, 13-20 (2015).

33. Barry, N. P. \& Sadler, P. J. Exploration of the medical periodic table: towards new targets. Chem. Commun. 49, 5106-5131 (2013).

34. King, A. M. et al. Aspergillomarasmine A overcomes metallo- $\beta$-lactamase antibiotic resistance. Nature 510, 503-506 (2014).

35. Sun, Z., Hu, L., Sankaran, B., Prasad, B. V. V. \& Palzkill, T. Differential active site requirements for NDM-1 $\beta$-lactamase hydrolysis of carbapenem versus penicillin and cephalosporin antibiotics. Nat. Commun. 9, 4524 (2018).

36. Martinez Molina, D. et al. Monitoring drug target engagement in cells and tissues using the cellular thermal shift assay. Science 341, 84-87 (2013).

37. Ho, P. L. et al. Complete sequencing of pNDM-HK encoding NDM-1 carbapenemase from a multidrug-resistant Escherichia coli strain isolated in Hong Kong. PLoS ONE 6, el7989 (2011).

38. Zhang, H. et al. Action and mechanism of the colistin resistance enzyme MCR-4. Commun. Biol. 2, 36 (2019).

39. Anandan, A. et al. Structure of a lipid A phosphoethanolamine transferase suggests how conformational changes govern substrate binding. Proc. Natl. Acad. Sci. USA 114, 2218 (2017)

40. Esposito, F. et al. Detection of colistin-resistant MCR-1-positive Escherichia coli by use of assays based on inhibition by EDTA and zeta potential. J. Clin. Microbiol. 55, 3454-3465 (2017).
41. Parenteral. JHP Pharmaceuticals (LLC, Rochester, 2011)

42. Linciano, P., Cendron, L., Gianquinto, E., Spyrakis, F. \& Tondi, D. Ten years with New Delhi metallo- $\beta$-lactamase-1 (NDM-1): from structural insights to inhibitor design. ACS Infect. Dis. 5, 9-34 (2019).

43. MacNair, C. R. et al. Overcoming mcr-1 mediated colistin resistance with colistin in combination with other antibiotics. Nat. Commun. 9, 458 (2018)

44. Wei, P. et al. Substrate analog interaction with MCR-1 offers insight into the rising threat of the plasmid-mediated transferable colistin resistance. FASEB J. 32, 1085-1098 (2018).

45. Angelucci, F. et al. Inhibition of schistosoma mansoni thioredoxin-glutathione reductase by auranofin: Structural and kinetic aspects. J. Biol. Chem. 284, 28977-28985 (2009).

46. Contel, M. Gold chemistry. Applications and future directions in the life sciences. Edited by Fabian Mohr. Angew. Chem. Int. Ed. Engl. 49, 250-251 (2010).

47. Kai, J. \& Wang, S. Recent progress on elucidating the molecular mechanism of plasmid-mediated colistin resistance and drug design. Int. Microb. 23, 355366 (2020).

48. Goss, C. H. et al. Gallium disrupts bacterial iron metabolism and has therapeutic effects in mice and humans with lung infections. Sci. Transl. Med. 10, eaat7520 (2018)

49. Steinbuch, K. B. \& Fridman, M. Mechanisms of resistance to membranedisrupting antibiotics in Gram-positive and Gram-negative bacteria. MedChemComm 7, 86-102 (2016).

50. Partridge, S. R. et al. Proposal for assignment of allele numbers for mobile colistin resistance (mcr) genes. J. Antimicrob. Chemother. 73, 2625-2630 (2018).

51. Bahr, G. et al. Clinical evolution of New Delhi metallo-beta-Lactamase (NDM) optimizes resistance under $\mathrm{Zn}$ (II) deprivation. Antimicrob. Agents Chemother. 62, e01849-17 (2018)

52. Harbut, M. B. et al. Auranofin exerts broad-spectrum bactericidal activities by targeting thiol-redox homeostasis. Proc. Natl. Acad. Sci. USA 112, 4453-4458 (2015).

53. Nation, R. L. et al. Dosing guidance for intravenous colistin in critically-ill patients. Clin. Infect. Dis. 64, 565-571 (2017)

54. National Institute of Allergy and Infectious Diseases (NIAID). Phase IIa Randomized, Single-Blinded, Placebo-Controlled Clinical Trial of the Reprofiled Drug Auranofin for GI Protozoa. NCT02736968; US National Library of Medicine, ClinicalTrials.gov (2020).

55. Yang, N. et al. Bismuth complexes inhibit the SARS coronavirus. Angew. Chem. Int. Ed. Engl. 46, 6464-6468 (2007).

56. Kabsch, W. XDS. Acta Crystallogr. D. Biol. Crystallogr. 66, 125-132 (2010).

57. McCoy, A. J. et al. Phaser crystallographic software. J. Appl. Crystallogr. 40, 658-674 (2007).

58. The CCP4 suite: programs for protein crystallography. Acta Crystallogr. D. Biol. Crystallogr. 50, 760-763 (1994).

59. Adams, P. D. et al. PHENIX: a comprehensive Python-based system for macromolecular structure solution. Acta Crystallogr. D. Biol. Crystallogr. 66 213-221 (2010).

60. Ma, G., Zhu, Y., Yu, Z., Ahmad, A. \& Zhang, H. High resolution crystal structure of the catalytic domain of MCR-1. Sci. Rep. 6, 39540 (2016).

61. Murshudov, G. N. et al. REFMAC5 for the refinement of macromolecular crystal structures. Acta Crystallogr. D. Biol. Crystallogr. 67, 355-367 (2011).

62. Emsley, P., Lohkamp, B., Scott, W. G. \& Cowtan, K. Features and development of Coot. Acta Crystallogr. D. Biol. Crystallogr. 66, 486-501 (2010).

63. Chen, V. B. et al. MolProbity: all-atom structure validation for macromolecular crystallography. Acta Crystallogr. D. Biol. Crystallogr. 66, $12-21$ (2010).

64. Schneider, C. A., Rasband, W. S. \& Eliceiri, K. W. NIH Image to ImageJ: 25 years of image analysis. Nat. Methods 9, 671-675 (2012).

\section{Acknowledgements}

We thank Drs. Menglong Hu, Yi Wang, and Ms. Yuan Wu for helpful discussion on crystallographic study; Dr. Ya Wang for help in microbiology experiments; Dr. KwanMing Ng for help in MALDI-TOF-MS, and Dr. Peng Gao for help in animal study. NDM-1-positive K. pneumonia isolate was kindly given by Prof. Patrick-Chiu Yat Woo. The crystal diffraction data were collected at Shanghai Synchrotron Radiation Facility (SSRF), the Chinese Academy of Sciences. We thank the staff at BL17U1 beamline of SSRF for their generous help. This work was supported by Research Grants Council of Hong Kong (R7070-18, 17307017), Health and Medical Research Fund (HKM-15-M10) and Seed Fund for Basic Research (201910159244).

\section{Author contributions}

H.S., H.L., and P.-L.H. conceived idea and designed experiments; R.W., Q.Z., and Y.-T $\mathrm{W}$. constructed the plasmids, overexpressed, purified the proteins, and performed all enzyme-based and cell-based experiments; Q.Z., H.W., and M.W. crystallized the 
proteins and solved the structures by X-ray crystallography; R.W. and Q.Z. performed animal experiments. Q.H. and A.Y. assisted in analysis of crystallography data. P.-L.H. and R.Y.-T.K. aided the biological interpretation of the microbiological and animal data. H.L., R.W., and H.S. drafted and revised the manuscript with input from all co-authors. All authors approved the final version of the manuscript.

\section{Competing interests}

H.S., P.-L.H., Q.Z., R.W., and H.L. have filed a patent application related to the work of this manuscript. The rest of the authors declare no competing interests.

\section{Additional information}

Supplementary information is available for this paper at https://doi.org/10.1038/s41467020-18939-y.

Correspondence and requests for materials should be addressed to H.S. or R.W.

Peer review information Nature Communications thanks Timothy Palzkill and Alejandro Vila for for their contribution to the peer review of this work. Peer reviewer reports are available.
Reprints and permission information is available at http://www.nature.com/reprints

Publisher's note Springer Nature remains neutral with regard to jurisdictional claims in published maps and institutional affiliations.

(c) (i)

Open Access This article is licensed under a Creative Commons Attribution 4.0 International License, which permits use, sharing, adaptation, distribution and reproduction in any medium or format, as long as you give appropriate credit to the original author(s) and the source, provide a link to the Creative Commons license, and indicate if changes were made. The images or other third party material in this article are included in the article's Creative Commons license, unless indicated otherwise in a credit line to the material. If material is not included in the article's Creative Commons license and your intended use is not permitted by statutory regulation or exceeds the permitted use, you will need to obtain permission directly from the copyright holder. To view a copy of this license, visit http://creativecommons.org/ licenses/by/4.0/.

(c) The Author(s) 2020 